\title{
O REGISTRO FÓSSIL DAS COBERTURAS SEDIMENTARES DO CRÁTON DO SÃO FRANCISCO EM MINAS GERAIS
}

\author{
Jonathas S. Bittencourt ${ }^{1}$, Matheus Kuchenbecker ${ }^{2}$, André Gomide Vasconcelos ${ }^{3}$, \\ Karin E. B. Meyer ${ }^{1}$
}

\begin{abstract}
1 - Instituto de Geociências, CPMTC e Departamento de Geologia, Universidade Federal de Minas Gerais, Av. Antônio Carlos 6627. $31270-901$. Belo Horizonte, MG, Brasil. E-mail: bittencourt.paleo@gmail.com, bohnsmeyer@yahoo.com.br

2 - Laboratório de Estudos Tectônicos/Núcleo de Geociências e Instituto de Ciência e Tecnologia, Universidade Federal dos Vales do Jequitinhonha e Mucuri, BR-367, Km 583, Alto da Jacuba, CEP 39100-000 Diamantina, MG, Brazil. E-mail: mk.geologia@gmail.com

3 - Programa de Pós-graduação em Geologia, Instituto de Geociências, Universidade Federal de Minas Gerais, Av. Antônio Carlos 6627. $31270-901$. Belo Horizonte, MG, Brasil. E-mail: andregomide86@gmail.com
\end{abstract}

Recebido em 26 de novembro de 2015; aceito em 30 de dezembro de 2015

Resumo: O registro fóssil dos depósitos sedimentares proterozoicos, paleozoicos e mesozoicos do Cráton do São Francisco inclui estruturas de origem microbiana (microbialitos, oncólitos), palinomorfos terrestres e marinhos, microfósseis silicosos e carbonáticos de origem marinha, metazoários neoproterozoicos, artrópodes, uma variedade de bioturbações, vertebrados actinopterígios, sarcopterígios e dinossauros. Com exceção dos microbialitos, que são amplamente distribuídos, os fósseis são relativamente escassos se comparados com a extensão geográfica dos depósitos e concentrados em alguns horizontes estratigráficos excepcionais. A raridade dos achados pode ser explicada pela falta de prospecção nas áreas mais distantes das localidades tradicionalmente conhecidas, e também ao baixo potencial de preservação dos fósseis em ambientes deposicionais do Meso e Neoproterozoico, ou de regimes climáticos extremos, i.e. glacial para o Paleozoico e desértico para as porções mesozoicas da Bacia Sanfranciscana. Trabalhos recentes de prospecção, no entanto, têm revelado um potencial significativo para novas descobertas, especialmente na região norte de Minas Gerais. Parte dos registros cenozoicos está distribuída em bacias restritas incluindo as de Gandarela e Fonseca (Eoceno-Mioceno), onde basicamente se preservaram folhas de angiospermas e gimnospermas, palinomorfos e insetos, e a Bacia de Juatuba, com registro predominante de folhas de angiospermas $O$ Quaternário constitui uma exceção do ponto de vista da diversidade e abundância de fósseis, especialmente devido à ampla ocorrência de mamíferos em sistemas cársticos. A descontinuidade dos depósitos sedimentares no Cráton do São Francisco mostram hiatos de cerca de 250 milhões de anos entre as seções fossilíferas do Neoproterozoico ao Paleozoico e de cerca de 125 milhões de anos (Eocretáceo ao Pleistoceno) para a fauna de vertebrados.

Palavras-chave: paleontologia, bacias sedimentares, registro fóssil, Proterozoico, Mesozoico, Cenozoico

Abstract: THE FOSSIL RECORD OF THE SEDIMENTARY COVERS OF THE SÃO FRANCISCO CRATON IN MINAS GERAIS. The fossil record of the Proterozoic, Paleozoic and Mesozoic sedimentary deposits of the São Francisco Craton includes microbial structures (microbialites and oncoliths), terrestrial and marine palynomorphs, siliceous and calcareous marine microfossils, Neoproterozoic metazoans, arthropods, a variety of bioturbations, actinopterygians, sarcopterygians and dinosaurs. Except for the microbialites, which are widely distributed, the fossils are relatively scarce if compared with the geographic extension of the deposits and concentrated in some exceptional sedimentary horizons. The rarity of the findings can be explained by the lack of fieldwork far from the localities traditionally explored, and the low potential of fossil preservation in paleoenvironments of Paleo and Mesoproterozoic or those under extreme climatic regimes, i.e. glacial for the Paleozoic rocks and desertic for most of the Mesozoic rocks within the Sanfranciscana Basin. On the other hand, recent works have revealed a significant potential for new discoveries, especially in northern Minas Gerais. Part of the Cenozoic record is distributed across restrict basins, including Gandarela and Fonseca (Eocene-Miocene), where basically leaves of angiosperms and gymnosperms, palynomorphs and insects are preserved, and the Juatuba Basin, with predominant record of angiosperm leaves. The Quaternary is an exception of fossil diversity and abundance, due to the widespread occurrence of mammals within karstic deposits. The discontinuity of the sedimentary deposits in the São Francisco Craton shows gaps in the fossil record, which encompass c. 250 my between the Neoproterozoic and Paleozoic, and c. $125 \mathrm{my}$ (Early Cretaceous to Pleistocene) for the vertebrate fauna.

Keywords: paleontology, sedimentary basins, fossil record, Proterozoic, Mesozoic, Cenozoic

\section{INTRODUÇÃO}

O Cráton do São Francisco (Almeida, 1977), assim como sua contraparte africana (Cráton do Congo), representa a porção interior e estável de um dos vários continentes que, ao final do Neoproterozoico, se amalgamaram para formar a porção ocidental do Supercontinente Gondwana (Brito Neves et al., 1999; Alkmin, 2004). Em sua longa história evolutiva, uma série de bacias sedimentares de idades e naturezas distintas se estabeleceram, fato que as torna altamente relevante do ponto de vista paleontológico.

À exceção dos fósseis da megafauna de mamíferos encontrados em depósitos quaternários desde o século 18 (Lund, 1950; Cartelle, 1994, 2012; Fernandes et al., 2012), os primeiros registros paleontológicos nas bacias sedimentares do Cráton do São Francisco, em Minas Gerais, referem-se a "madeiras" permineralizadas descobertas próximas ao Rio São Francisco (Liais, 1872; Freyberg, 1965). Estudos posteriores localizaram a ocorrência de vegetais fósseis em folhelhos da região de Presidente Olegário, ocasião em que os primeiros vertebrados fósseis, i.e. actinopterígios do gênero Dastilbe, foram reportados (Scorza \& Santos, 1955). Microfósseis foram mencionados posteriormente (Barbosa, 1965; Lima, 1979), à época em que foram descritos microbialitos nas seções proterozoicas dos 
grupos Bambuí e Vazante (Cassedanne, 1965, 1968; Dardenne et al., 1972; Moeri, 1972; Cloud \& Dardenne, 1973; Marchese, 1974). As descobertas mais recentes se referem a ossos de dinossauros saurísquios e metazoários ediacaranos coletados no norte de Minas Gerais (Zaher et al., 2011; Warren et al., 2014).

O conhecimento acumulado até o momento sobre o registro fóssil das coberturas sedimentares pré-cenozoicas do Cráton do São Francisco é esparso. Parte dos registros mais antigos necessita revisão e muitas das descobertas recentes ainda foram pouco exploradas, sugerindo a necessidade de avaliar de forma integrada as ocorrências fósseis. Neste contexto, este artigo visa fornecer um panorama da pesquisa paleontológica das bacias sedimentares do Cráton do São Francisco, com foco em Minas Gerais, por meio de um levantamento das ocorrências fósseis já publicadas, tanto na literatura especializada, quanto em programas de mapeamento, com o intuito de dimensionar mais acuradamente o potencial paleontológico da região.

\section{CONTEXTO GEOLÓGICO}

As bordas das placas continentais que formaram a Gondwana, incluindo a porção referente ao Cráton do São Francisco, juntamente com rochas sedimentares das bacias que se estabeleceram sobre elas, foram deformadas durante processos colisionais, dando origem a um extenso sistema de cinturões orogênicos que envolvem as áreas cratônicas remanescentes (Fig. 1). Em Minas Gerais, levando-se em conta o atual cenário geotectônico, estas diferentes bacias encontram-se registradas em pelo menos três compartimentos distintos: o Cráton do São Francisco e dois de seus cinturões orogênicos, a Faixa Brasília, a oeste, e o Orógeno Araçuaí, a leste (Fig. 1-3) (Alkmin \& Martins-Neto, 2001; Alkmin, 2004).

Com relação às coberturas sedimentares, merecem destaque alguns ciclos bacinais (Fig. 3). Entre o Neoarqueano e o início do Paleoproterozoico, desenvolveu-se na região que hoje compõe o sul do Cráton do São Francisco uma bacia de margem passiva onde se depositaram as unidades inferiores do Supergrupo Minas, em ambiente plataformal, sobre substrato siálico (Alkmin \& Marshak, 1998). Nos períodos Riaciano e Orosiriano $(2,1-1,9 \mathrm{Ga})$, durante a Orogênese Transamazônica, ocorreu a inversão desta bacia e a consequente formação de uma bacia de antepaís, onde foram depositadas as unidades superiores do Supergrupo Minas (Reis, 2011).
No Supergrupo Minas, as formações Gandarela e Fecho do Funil, datadas do Paleoproterozoico, hospedam oncólitos e estromatólitos (Dardenne \& Campos Neto, 1975; Souza \& Müller, 1984; Kuchenbecker et al., 2015a). A primeira é composta basicamente de mármore dolomítico e filitos, enquanto que a segunda corresponde a uma sucessão de filitos com eventuais lentes dolomíticas (Dorr, 1969).

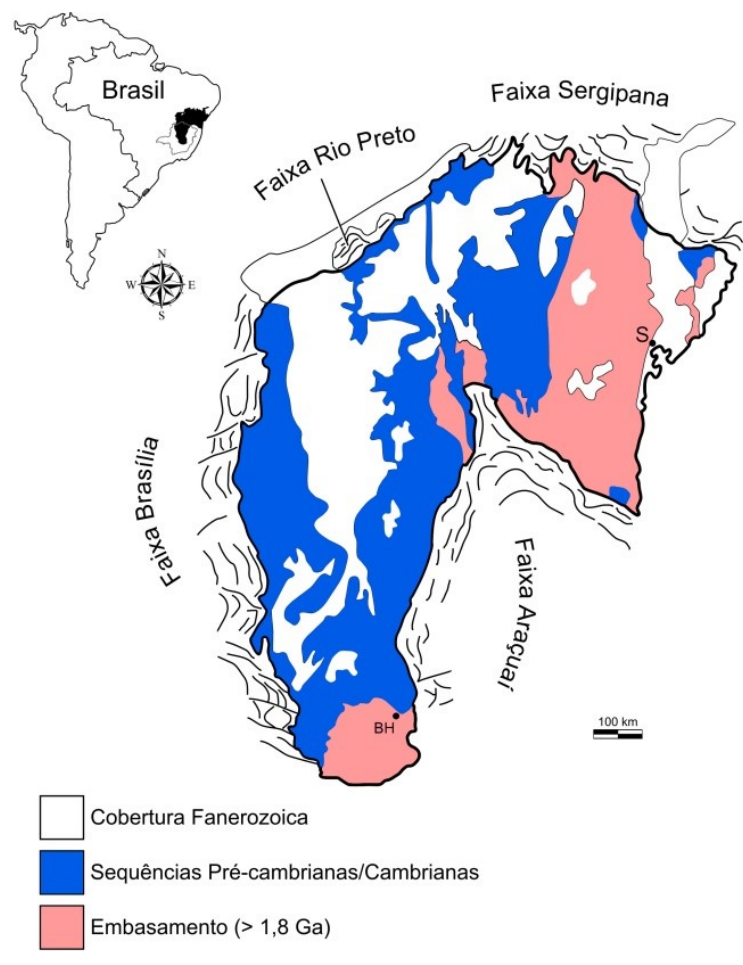

$\mathrm{BH}$ - Belo Horizonte; S - Salvador

Figura 1. Mapa geológico geral do Cráton do São Francisco. Modificado de Alkmin (2004).

No período Estateriano (c. 1,7 Ga) toda a região foi submetida a esforços distensivos, que levaram à formação de um amplo sistema ensiálico de riftes (Alkmin, 2004). A leste do atual limite do cráton, uma grande calha de orientação meridiana foi preenchida pelas unidades inferiores do Supergrupo Espinhaço. Braços secundários deste rifte, de direção NW, foram abertos no interior da atual área cratônica, dando origem a aulacógenos (Paramirim e Pirapora, Alkmin, 2004; Reis, 2011). Já no Mesoproterozoico, essas bacias teriam apresentado processos de subsidência térmica que acomodaram a deposição das unidades superiores do Supergrupo Espinhaço (Martins-Neto et al., 2001). A oeste do atual limite do cráton, por sua vez, foram abertas calhas rifte, que receberam os sedimentos atribuídos ao Grupo Araí. Posteriormente, esta bacia teria evoluído para uma margem passiva de mar epicontinental, onde teriam se depositado as unidades do Grupo Paranoá (Campos et al., 2013). 


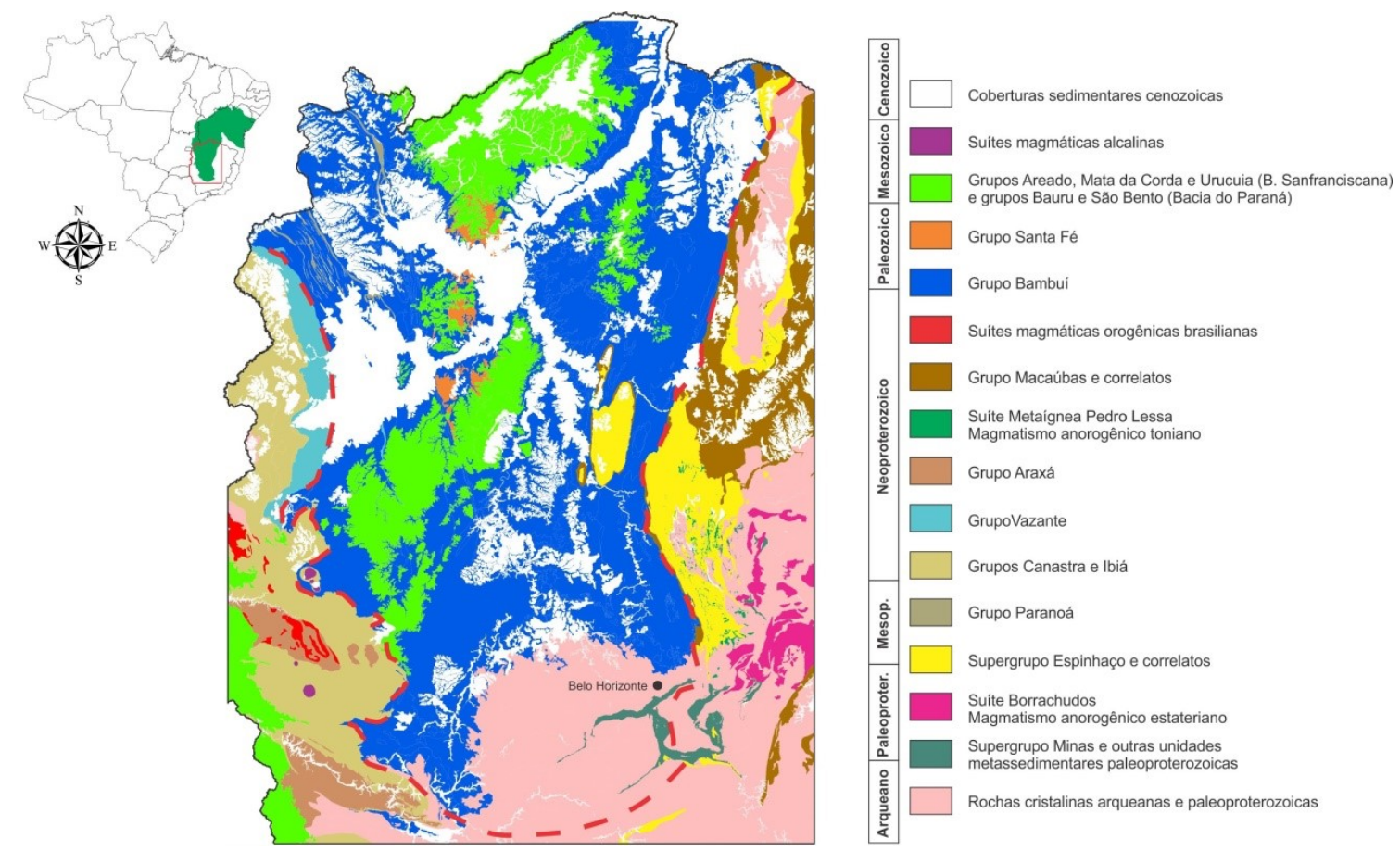

Figura 2. Mapa geológico detalhado do Cráton do São Francisco.

No Supergrupo Espinhaço, a Formação Rio Pardo Grande - unidade superior do Grupo Conselheiro Mata - apresenta camadas de dolomito estromatolítico, que afloram na borda oeste da Serra do Espinhaço, nas proximidades de Rodeador (Schöll \& Fogaça, 1980). Do Grupo Paranoá, merecem destaque as formações Ribeirão Piçarrão e Córrego do Barreiro, aflorantes no domínio da Faixa Brasília, que hospedam estromatólitos de diversas naturezas (Campos et al., 2013). Já no domínio cratônico, as unidades Inferior e Superior do Grupo Paranoá apresentam frequentes lentes de dolomito estromatolítico (Alvarenga, 1978; Alvarenga et al., 2012; Kuchenbecker et al., 2015b).

No período Toniano (c. $900 \mathrm{Ma}$ ), novos processos extensionais culminaram na abertura de bacias a leste e a oeste do traçado atual do Cráton do São Francisco. A leste, desenvolveu-se uma bacia rifte, onde se sedimentaram as unidades inferiores do Grupo Macaúbas, incluindo as seções dolomíticas da Formação Domingas (Noce et al., 1993; Fraga et al., 2014). Depois de dois episódios de rifteamento, a bacia teria evoluído para uma margem passiva parcialmente oceanizada, onde se depositaram as unidades de topo do grupo (Pedrosa-Soares et al., 2011; Kuchenbecker et al., 2015b). No lado oeste, por sua vez, desenvolveu-se uma extensa plataforma onde se sedimentaram as unidades pelíticas e carbonáticas do Grupo Vazante, em processos bacinais ainda pouco compreendidos (Rodrigues et al., 2012).
Entre o final do Neoproterozoico e o início do Cambriano (c. 600-500 Ma), diversas massas continentais se amalgamaram para formar a porção ocidental do Supercontinente Gondwana (Alkmin, 2004). No paleocontinente São Francisco-Congo precursor do atual Cráton do São Francisco - a carga promovida pela edificação dos orógenos Brasília, a oeste, e Araçuaí, a leste, deu origem a uma complexa bacia foreland, que recebeu os sedimentos do Grupo Bambuí (Martins-Neto et al., 2001; Reis, 2011; Kuchenbecker, 2014).

O Grupo Bambuí é a principal unidade de cobertura cratônica, ocorrendo em uma vasta área nos estados de Minas Gerais, Bahia e Goiás. Merecem destaque, sob o ponto de vista paleontológico, as formações Sete Lagoas e Lagoa do Jacaré, ambas compostas por calcário, que abrigam diversas ocorrências de estromatólitos (Fantinel et al., 2015).

Após um período de relativa estabilidade tectônica, a região do Cráton do São Francisco voltaria a atuar como sítio deposicional no final do Paleozoico. Durante a transição entre os períodos Carbonífero e Permiano foram depositadas as unidades do Grupo Santa Fé (Bacia Sanfranciscana), que registram uma importante glaciação (Campos \& Dardenne, 1994). A subsidência responsável pela acomodação da unidade estaria relacionada a movimentos verticais de baixa intensidade dos orógenos Brasília e Araçuaí (Alkmin \& Martins-Neto, 2001). 


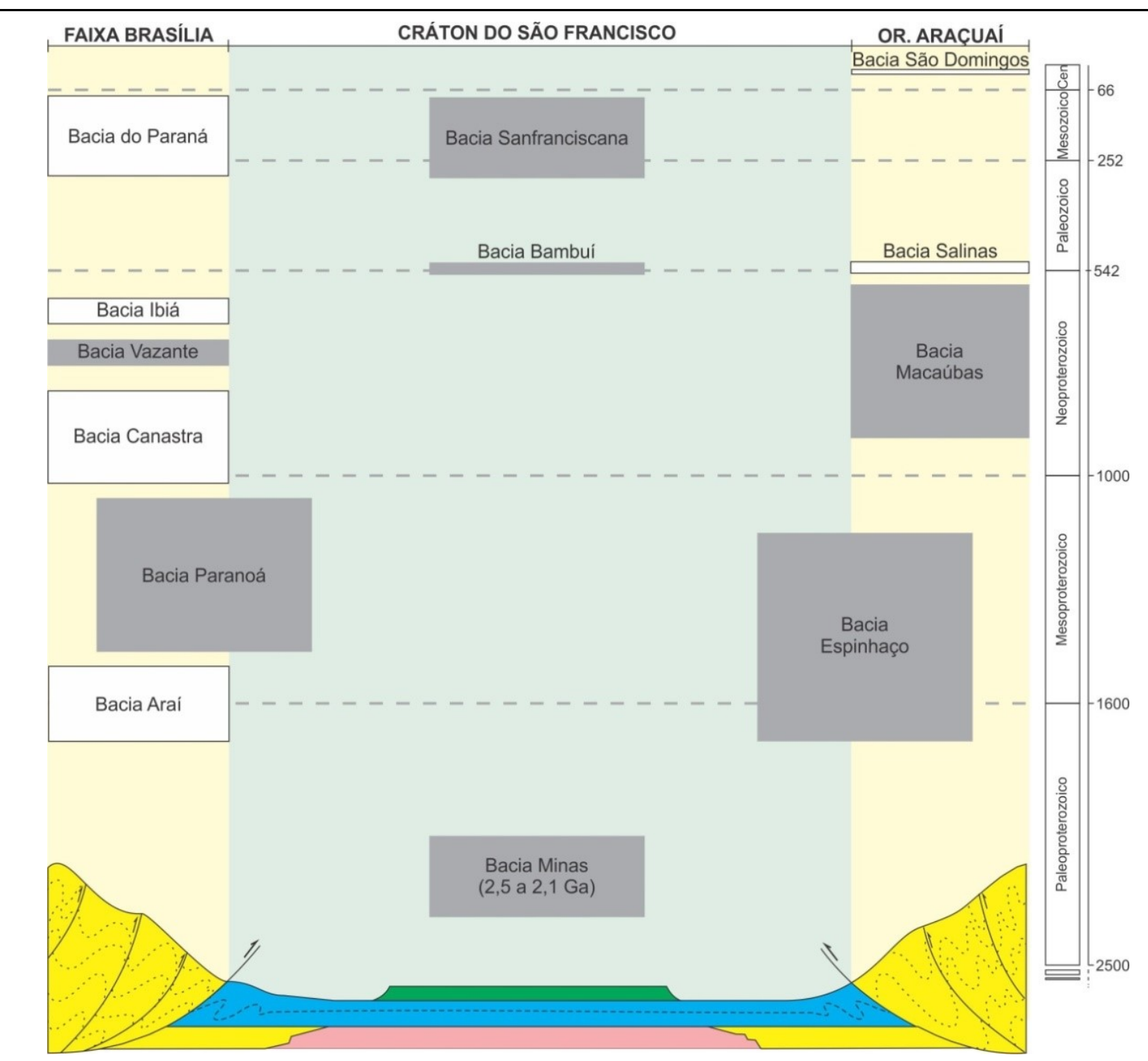

Figura 3. Relação espacial entre o Cráton do São Francisco, seus orógenos marginais e as bacias sedimentares que se desenvolveram sobre eles ao longo do tempo. Notar que algumas bacias se estendem sobre o cráton e orógeno, ou são restritas a um deles. No caso da Bacia do Paraná, apenas uma pequena parte de suas rochas aflora sobre a Faixa Brasília.

No início do Cretáceo (Fig. 3), os esforços distensivos decorrentes da abertura do Oceano Atlântico tiveram importantes reflexos no interior da plataforma brasileira. Na região do Cráton do São Francisco, houve a deposição das unidades do Grupo Areado, predominantemente em ambientes de sedimentação continentais (Campos \& Dardenne, 1997a). Posteriormente, a Bacia Sanfranciscana foi marcada por um importante evento magmático alcalino, registrado nas rochas de afinidade vulcânica do Grupo Mata da Corda (Campos \& Dardenne, 1997b). A evolução da bacia alcançou o Neocretáceo, quando se depositaram as unidades do Grupo Urucuia, em um amplo ambiente desértico-fluvial (Campos \& Dardenne, 1997a, b; Sgarbi et al., 2001).

O Grupo Areado corresponde aos afloramentos de maior interesse paleontológico da Bacia Sanfranciscana. É tradicionalmente subdividido nas formações Abaeté, Quiricó e Três Barras (Campos \&
Dardenne, 1997a, b; Sgarbi et al., 2001), as duas últimas mais importantes do ponto de vista paleontológico. A Formação Quiricó (Campos \& Dardenne, 1997a) é predominantemente composta de sedimentos pelíticos, como folhelhos e siltitos, com intercalações de arenitos com estratificação cruzada cada vez mais comuns em direção ao topo. Sua faciologia é consensualmente representativa de ambiente lacustre, como atestada por abordagens estratigráficas tradicionais (Moraes et al., 1986; Sgarbi, 1989) e de estratigrafia de sequências (Kattah, 1991; Mendonça, 1999, 2003). Na região de Presidente Olegário, ocorrem folhelhos ricos em bioclastos (Scorza \& Santos, 1955). Como apontado por diversos autores (e.g., Kattah, 1991; Campos \& Dardenne, 1997a), estes folhelhos tem espessura reduzida e representam uma porção mais profunda do sistema lacustre.

Prospecções recentes realizadas mais ao norte na bacia, incluindo as folhas Ibiaí e Coração de Jesus, 
demonstraram a ocorrência de níveis silto-argilosos com acamamento convoluto, associados a horizontes de calcrete e lentes de arenito, aparentemente correlatas à Formação Quiricó, mas que podem representar uma nova unidade litoestratigráfica (Pires-Domingues, 2009). Para a Formação Três Barras, são descritas fácies associadas à deposição eólica e flúvio-deltaica (Sgarbi, 1991; Campos \& Dardenne, 1997a), com registro de bioturbações e microfósseis marinhos (Kattah \& Koutsoukos, 1992; Carvalho \& Kattah, 1998).

Os depósitos cenozoicos de interesse paleontológico incluem as bacias de Fonseca (Eoceno-Oligoceno), Gandarela (Eoceno-Mioceno) e Juatuba (idade indeterminada), além dos depósitos cársticos quaternários desenvolvidos em calcários e rochas ferruginosas (Gorceix, 1884; Lund, 1950; Fonseca \& Costa, 1971; Lima \& Salard-Cheboldaeff, 1981; IGA, 1982; Sgarbi et al., 1992; Cartelle, 1994; Sant'Anna \& Schorscher, 1997; Maizatto, 2001; Mello et al., 2002; Cartelle, 2012; Frank et al., 2012; Bittencourt et al., 2015). As duas primeiras, assentadas sobre embasamento pré-cambriano, são bacias fluviais com morfologia tipo graben e semigraben, respectivamente, resultantes de esforços tectônicos distensivos nas porções orientais da Plataforma Sul-americana durante o Cenozoico (ver revisão de Fanton, 2013). A Bacia de Juatuba também tem origem fluvial e pode estar relacionada à antiga calha do rio Paraopeba (IGA, 1982).

\section{REGISTRO FÓSSIL}

3.1. Estruturas microbianas - microbialitos, oncólitos e micro-organismos

Microbialitos são definidos como depósitos organossedimentares acrecionais, resultantes do trapeamento e deposição de sedimentos detríticos e/ou da precipitação mineral por uma comunidade microbiana bentônica (Riding, 2011), e incluem os estromatólitos, trombólitos, dendrólitos, leiólitos e laminitos microbianos (Aitken, 1967; Kennard \& James, 1986; Riding, 1999; Riding, 2011 ). Oncólitos, ou as rochas ricas em oncoides, são semelhantes aos microbialitos, embora com formato esférico a elipsoide, lâminas irregulares, parcialmente sobrepostas, e não fixos ao substrato (Tucker \& Wright, 1990; Flügel, 2010). Os microbialitos variam quanto à fábrica: estromatólitos e laminitos microbianos são laminares; trombólitos estruturamse em grumos, dendrólitos são conjuntos ramificados e leiólitos são afaníticos (Riding, 2011). Estromatólitos, notadamente as estruturas microbianas mais comuns do Pré-Cambriano, têm distribuição cosmopolita e amplitude estratigráfica do Arqueano ao Recente, dando-Ihes o status de mais antigos e longevos registros de vida na Terra (Awramik, 1990; Grotzinger \& Knoll, 1999; Riding, 2007).

No Cráton do São Francisco, os pontos de ocorrência de microbialitos proterozoicos estão amplamente distribuídos (Fig. 4).
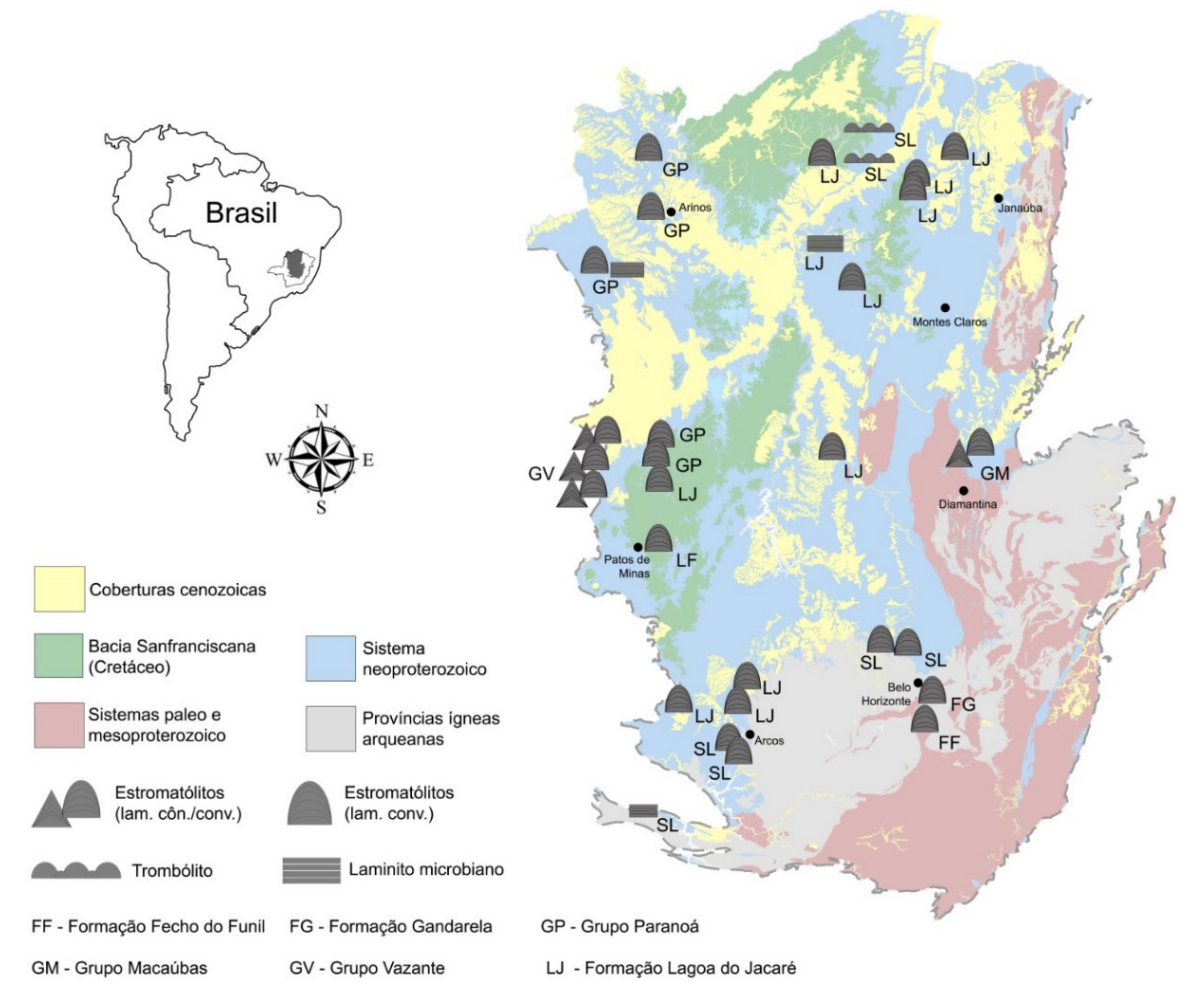

Figura 4. Mapa geológico do Cráton do São Francisco (modificado de CPRM/CODEMIG, 2014), mostrando a localização dos principais afloramentos com microbialitos proterozoicos. Os estromatólitos foram identificados pelo padrão de laminação (lam.): cônica (côn.) ou convexa (conv.). Compilado de diversas fontes (ver texto). 
Os estromatólitos mais antigos do Cráton (Fig. $5 a-b)$ estão associados à Formação Gandarela e às lentes de dolomito da Formação Fecho do Funil, Supergrupo Minas, depositadas entre 2,4 e 2,1 Ga (Dardenne \& Campos Neto, 1975; Cassedanne \& Cassedanne, 1978; Pinto, 1984; Souza \& Müller, 1984; Renger et al., 1994; Babinski et al., 1995; Fairchild et al., 2012). Em ambos, há oncólitos associados. Para os microbialitos da Formação Fecho do Funil, há uma ampla variação morfológica, incluindo tipos colunares estreitos, tuberosos e irregulares, além de dômicos e estratiformes (Kuchenbecker et al., 2015a).
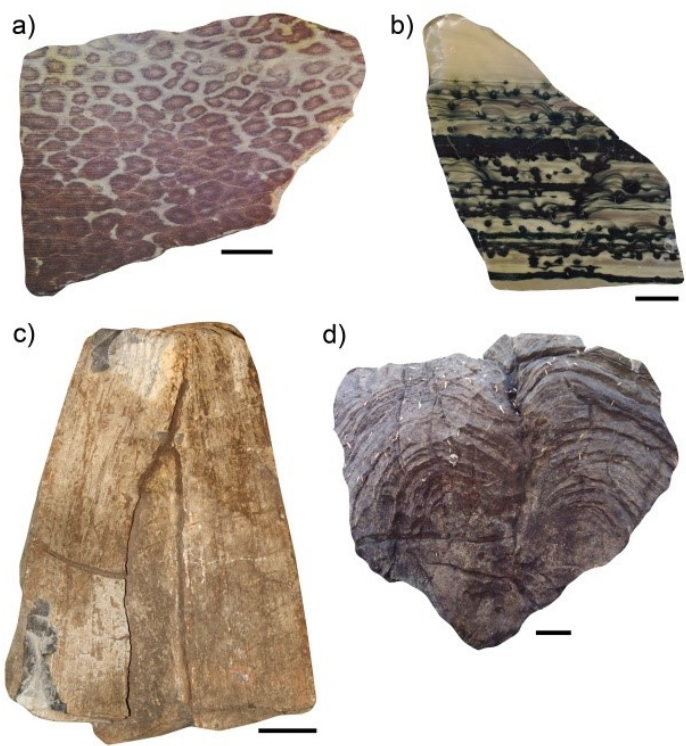

Figura 5. Exemplos de microbialitos do Cráton do São Francisco incluindo: a) Estromatólitos colunares da Pedreira Cumbi; b) Estromatólitos e oncoides da Formação Gandarela; c) Conophyton do Grupo Vazante; d) Estromatólito do Grupo Paranoá. Escalas: a $=5 \mathrm{~cm} ; b=2 \mathrm{~cm} ; c, d=4 \mathrm{~cm}$.

Historicamente na Bacia Bambuí, microestruturas de possível origem microbiana preservadas em calcário da região de Sete Lagoas foram reportadas na literatura antes dos microbialitos com feições macroscópicas (Cassedanne, 1965). Estromatólitos propriamente ditos foram primeiramente descritos entre o final da década de 60 e início de 70 (Cassedanne, 1968; Barbosa et al., 1970), na região de Vazante, noroeste de Minas Gerais. Estudos sistemáticos executados por diversos autores (Dardenne et al., 1972; 1972; 1973) detalharam a ocorrência de Conophyton no sítio Cabeludo. Trabalhos posteriores adicionaram dados sobre os microbialitos e oncólitos de localidades próximas a Lagamar (Valeriano et al., 2004; Sallun Filho \& Fairchild, 2005; Dardenne et al., 2009; Favoreto et al., 2011). Inicialmente, pelo menos parte das sequências pelito-dolomíticas aflorantes nas regiões citadas acima eram associadas ao Grupo Bambuí (Barbosa et al., 1970; Dardenne et al., 1972; Moeri, 1972), o que foi posteriormente modificado pela associação ao Grupo Vazante
(Dardenne, 2000), nas porções externas da Faixa Brasília, próximo ao limite do Cráton do São Francisco.

A sucessão estromatolítica que aflora em diversas localidades do Membro Sumidouro da Formação Lagamar (Grupo Vazante) mostra uma diversidade morfológica significativa. Em Vazante, Cassedanne (1968) encontrou formas SH-V, segundo a classificação tradicional de Logan et al. (1964), caracterizadas por colunas de laminação macroscópica arredondada (hemisferoides empilhados), com diâmetro basal variável, sucedidas por formas LLH-S (pseudocolunas com ligação lateral espaçada), além de raras construções cônicas. Em Lagamar, Favoreto et al. (2011, p. 50) encontrou, além dos microbialitos planares, ondulados, cumulados e oncoides, 11 morfótipos de estromatólitos, três dos quais coniformes (Fig. 5c) e os demais com forma laminar macroscópica convexa, com colunas cilíndricas ou subcilíndricas, ramificados ou não, turbinados ou decumbentes, com ou sem ligação lateral por pontes. Diferenças na macro e microestrutura das construções estromatolíticas do tipo Conophyton já haviam sido notadas quando espécimes das regiões de Cabeludo e Lagamar foram comparados (Sallun Filho \& Fairchild, 2005).

Em geral, infere-se que estromatólitos coniformes testemunhem ambientes de águas calmas ou mais profundos que o limite infralitorâneo, mas não abaixo da zona fótica, enquanto que colunas de laminação convexa são típicos de zonas intermarés (Logan et al., 1964). Nos estromatólitos coniformes do Grupo Vazante, intraclastos e feições erosivas por exposição subaérea são incomuns (Moeri, 1972; Dardenne, 2009), o que confirma a suposição de bioconstrução em ambientes mais profundos. Por outro lado, a ocorrência intercalada de estruturas microbianas colunares com laminação macroscópica hemisferoidal ou planares, com abundância de intraclastos e lamas micríticas, sugerem mudanças de profundidade associadas a ciclos regressivos (Nogueira \& Dardenne, 1992; Dardenne et al., 2009; Favoreto et al., 2011). No Grupo Macaúbas, morfótipos semelhantes aos de Vazante e de outras regiões do país, referidos como Conophyton e Jacutophyton em associação, foram também inferidos como de ambiente mais profundo, com aportes transitórios de maior energia resultantes de alterações ambientais, incluindo possível mudança no nível de base (Fraga et al., 2013),

Ocorrências adicionais de estromatólitos cônicos foram reportadas (sem localização exata) para a Folha João Pinheiro, na denominada 'Associação de fácies $A^{\prime}$, que inclui calcários dolomíticos e laminitos 
microbianos, segundo os autores, correlacionáveis ao Grupo Paranoá (Oliveira et al., 2003), que também tem ocorrências de estromatólitos (Fig. $5 \mathrm{~d}$ ). Também dentro dos limites do Cráton, em Minas Gerais, estromatólitos, trombólitos e laminitos microbianos foram encontrados em pacotes carbonáticos do Grupo Bambuí, especificamente nas formações Sete Lagoas, Lagoa do Jacaré e Lagoa Formosa (Marchese, 1974; Lima et al., 2007; Vieira et al., 2007; Iglesias \& Uhlein, 2009; Fragoso et al., 2011b), além dos já mencionados estromatólitos do Grupo Macaúbas (Schöll, 1976; Schöll \& Fogaça, 1980; Fraga et al., 2013). Uma revisão recente (Sanchez, 2014) demonstra um grande potencial para novas descobertas, já que muitas das ocorrências de estromatólitos no Grupo Bambuí foram pouco estudadas.

No Grupo Bambuí, estromatólitos foram primeiramente reportados em calcários do Membro Lagoa Santa da Formação Sete Lagoas (Fig. 6), próximo a Belo Horizonte (Marchese, 1974). Nestes afloramentos, há bioconstruções de até seis metros de altura, contendo uma sucessão de formas colunares de laminação convexa, com ou sem ligação lateral, e variação lateral de morfótipos (Marchese, 1974). Na região que engloba os municípios de Arcos e Pains, ocorrem afloramentos de rochas carbonáticas da Formação Sete Lagoas (Babinski, 1993; Lopes, 1995; Kuchenbecker et al., 2011), com abundante registro de microbialitos (ver abaixo) e uma grande variedade de microfitólitos (Nobre \& Coimbra, 2000). Mais ao norte, na região de Luz e Bom Despacho, as rochas carbonáticas com ocorrência de microbialitos são referidas à Formação Lagoa do Jacaré (Kuchenbecker, 2011; Seer \& Moraes, 2011).

Os estromatólitos que afloram próximo a Pains e Arcos são muito heterogêneos na morfologia macroscópica, incluindo construções nodulares, colunares (eretos e decumbentes), sub-planares e peseudocolunares, com laminação convexa a subretangular, de ampla variação de comprimento lateral, com ramificações dicotômicas ou múltiplas e perfis arredondados a elípticos irregulares em seção transversal (Fig. 7a-c; Sanchez, 2014). Estudos adicionais são necessários para se determinar se os demais registros de microbialitos nas formações Sete Lagoas e Lagoa do Jacaré, incluindo localidades das folhas Barreiro da Jaíba e Ubaí (Kuchenbecker et al., 2013; Kuchenbecker \& Costa, 2013; Uhlein et al., 2013), ou até mesmo a ocorrência de estromatólitos colunares em blocos associados à Formação Lagoa Formosa (Uhlein et al., 2011), em Patos de Minas (Fig. 7d), são correlatos às bioconstruções da região de Pains.
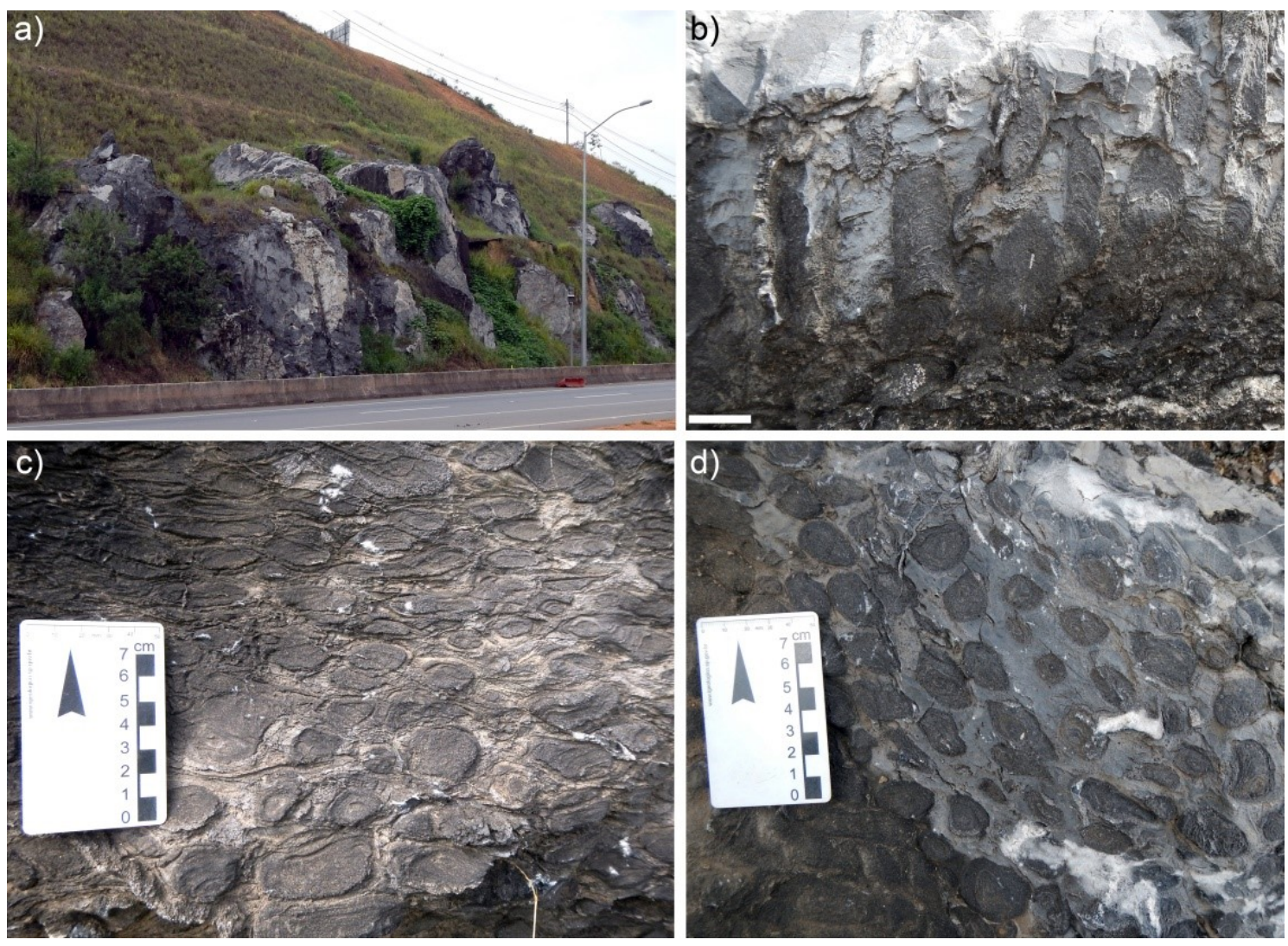

Figura 6. Estromatólitos da região de Sete Lagoas, mostrando: a) visão geral dos calcários contendo as bioconstruções; b) colunas estromatolíticas; c) e d) colunas estromatolíticas em seção transversal. Escala $b=20 \mathrm{~mm}$. 

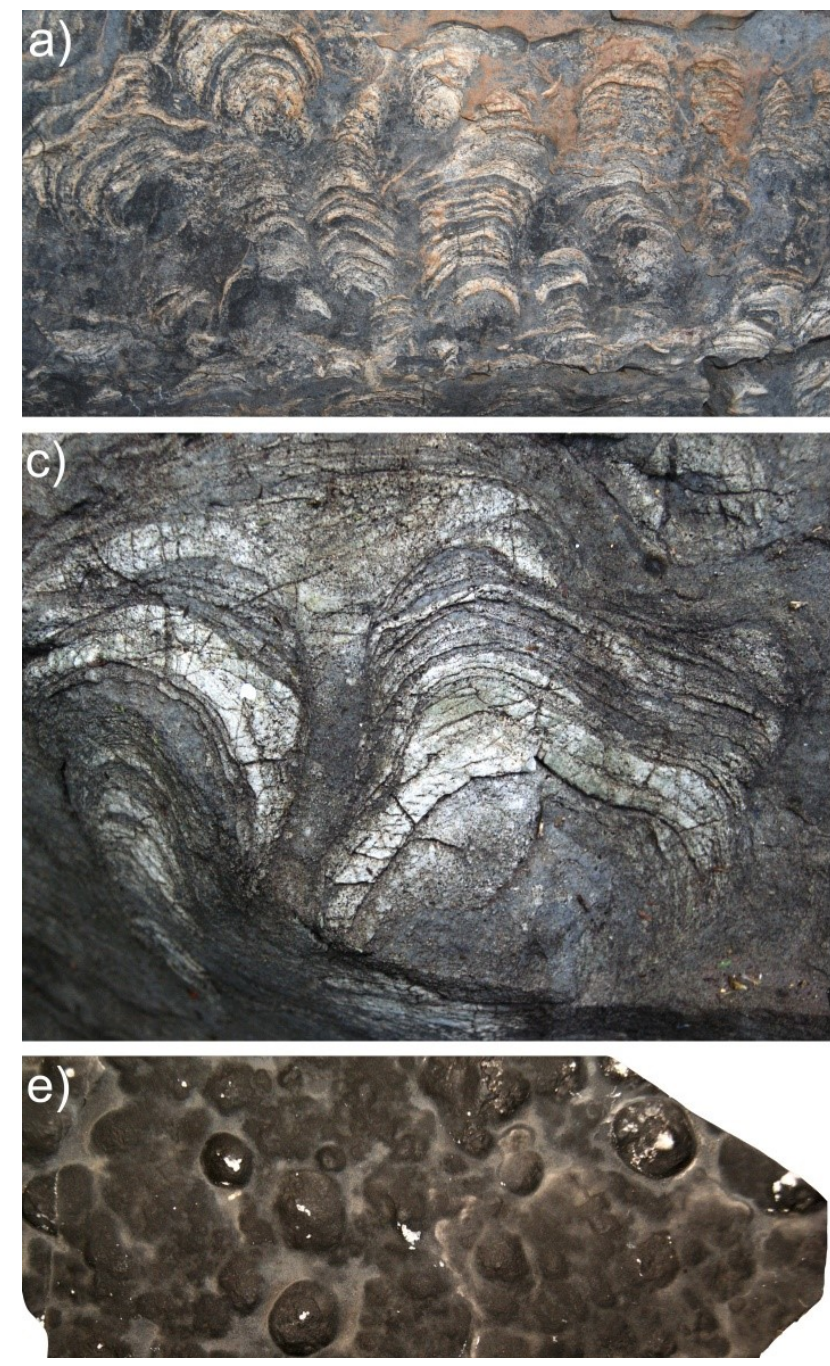

Figura 7. Microbialitos da Bacia Bambuí em Minas Gerais, incluindo estromatólitos a) colunares ramificados; b) dômicos pseudorramificados; c) com forma laminar sub-retangular, todos da região de Pains; d) estromatólitos colunares de Lagoa Formosa; e) construções trombolíticas da região de Januária.

No norte de Minas, trombólitos e laminitos microbianos foram registrados na Formação Sete Lagoas, juntamente com metazoários neoproterozoicos (Warren et al., 2014). Os trombólitos da região de Januária são reconhecidos pelo aspecto grumoso (nodular) típico. Os nódulos centimétricos podem ser arredondados ou irregulares (Fig. 7e). No caso dos primeiros, eles são mais altos e se destacam em relevo se comparados com os irregulares. A superfície dos nódulos centimétricos é formada de subunidades milimétricas, também de aspecto grumoso.

Evidências diretas de microfósseis associados às estruturas de biodeposição em rochas da Bacia do São Francisco têm sido relatadas em estromatólitos silicificados da Formação Sete Lagoas, na região de Unaí (Fairchild \& Dardenne, 1978; Fairchild \& Subacius, 1986; Simonetti \& Fairchild, 1989; Sanchez, 2014). Microfósseis em fácies correlatas de rochas do Grupo Bambuí, em Goiás, também já
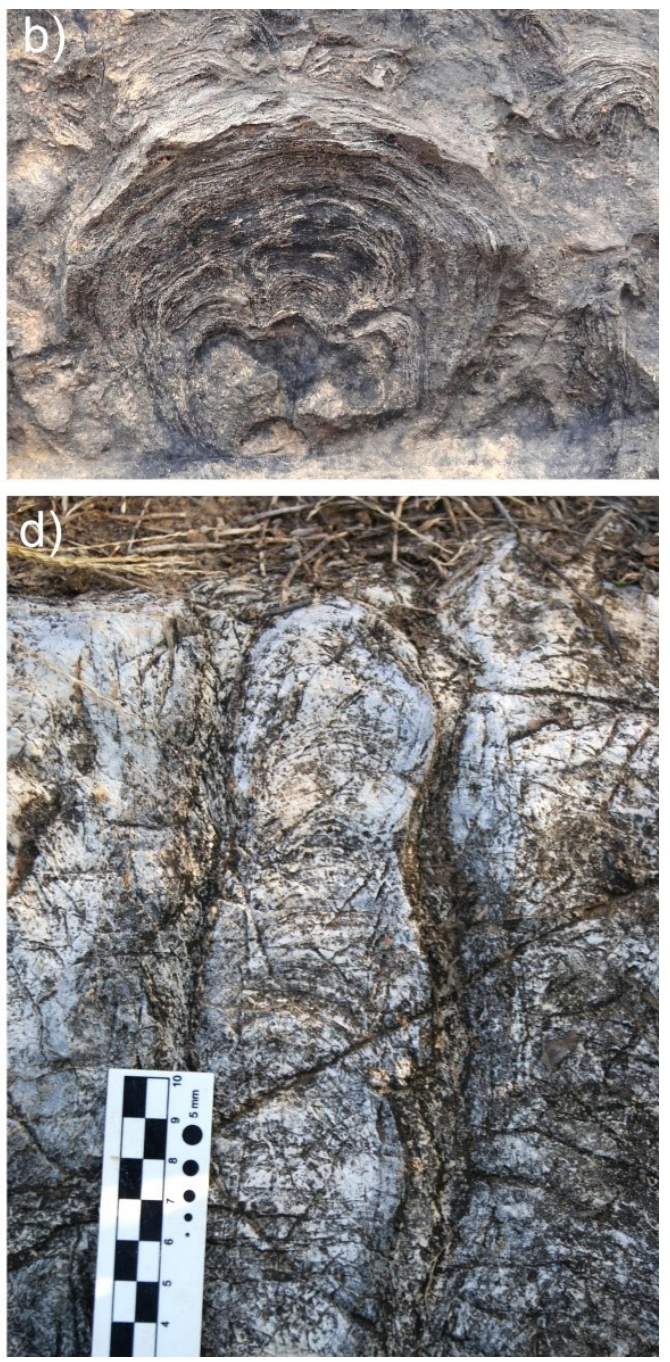

foram descritos (Fairchild \& Dardenne, 1978; Fairchild et al., 1980).

Pelo menos cinco gêneros de cianobactérias, distribuídos minimamente em Oscillatoriales e Chroococcales, já foram descobertas no sílex negro associado aos estromatólitos da região de Unaí (Simonetti \& Fairchild, 1989). Em rochas do Grupo Conselheiro Mata (Supergrupo Espinhaço) e da Formação Sete Lagoas, no norte de Minas, foi relatada, além de diversos gêneros de cianobactérias, uma abundante flora de acritarcos Leiosphaeridia (Simonetti \& Fairchild, 2000; Sanchez, 2014), gênero do qual faz parte Bambuites erichsenii (Sommer, 1971; Sanchez, 2014). Tais ocorrências sugerem uma correlação com as assembleias típicas do final do Neoproterozoico (Gaucher \& Sprechmann, 2010). Acritarcos também foram preliminarmente reportados para carbonatos da região de Januária (Quadros, 1987), Arcos (Cruz \& Lopes, 1992) e do Grupo Vazante (Baptista et al., 2010). 


\subsection{Palinomorfos fanerozoicos e matéria orgânica amorfa}

Lima (1979) e Arai et al. (1995) identificaram dezenas de táxons de palinomorfos terrestres (ver também Carvalho et al., 1994), entre grãos de pólen e esporos, nos folhelhos da Formação Quiricó, na região de Presidente Olegário, levantando questões sobre a idade e o ambiente deposicional do Grupo Areado.

Vale destacar o registro da palinozona Transitoripollis (= Tucanopollis) crisopolensis (Arai et al., 1995), confirmando hipótese prévia da idade mínima barremiana para aquela formação (Lima, 1979). Adicionalmente, grãos de Afropollis foram encontrados nos níveis superiores ao de Dastilbe, mas inferiores aos de silexito (ver seção 3.4), sugerindo deposição aptiana para os pacotes sobrepostos aos folhelhos carbonáticos (Arai et al., 1995). No entanto, além do trabalho de Lima (1979), os grãos de pólen foram figurados apenas em teses e dissertações (Sgarbi, 1997; Fragoso, 2011), não ficando claro quais horizontes exatamente foram amostrados para o trabalho palinológico.

Há um consenso de que os depósitos mesozoicos do Grupo Areado correspondem a um ambiente deposicional de clima quente e seco, variando de semiárido a desértico (Grossi Sad et al., 1971; Suguio \& Barcelos, 1983). Segundo Lima (1979), os palinomorfos da Formação Quiricó sugerem uma amenização regional do clima por um período relativamente curto, mas esta hipótese não foi confirmada por outros autores (Arai et al., 1995).

Uma análise de palinofácies nos folhelhos da região de Presidente Olegário (Fragoso, 2011) caracterizou, pela primeira vez, componentes orgânicos do querogênio na sequência cretácica da Bacia, incluindo matéria orgânica amorfa, fitoclastos e palinomorfos (Fig. 8). Análises quantitativas e qualitativas da matéria orgânica particulada sugerem a existência de três intervalos palinofaciológicos, associados a um sistema lacustre anóxico, inicialmente de baixa energia, mas com aumento de contribuição fluvial e diminuição da coluna de água em direção ao topo (Fragoso, 2011).

Para o Cenozoico, uma grande variedade de palinomorfos foi descrita para as bacias de Gandarela e Fonseca, incluindo táxons de fungos, a alga Botryococcus, pteridófitas, gimnospermas e angiospermas (Maizatto, 2001). As coberturas quaternárias do cráton também foram objeto de estudos palinológicos, com vistas à reconstrução paleoclimática e ao estudo da evolução do cerrado (e.g. Meyer et al., 2014).

\subsection{Vegetais}

Vegetais fósseis foram os primeiros registros paleontológicos mencionados na literatura para a
Bacia Sanfranciscana. Liais (1872) cita lenhos silicificados de dicotiledôneas em arenito sobreposto discordantemente ao calcário no vale do São Francisco, próximo a Indaiá. Uma localização mais precisa destes registros não é fornecida, tornandoos elusivos. Freyberg (1932 in 1965) reportou materiais mais completos da região de Patos de Minas, referindo troncos fossilizados incompletos a Araucarioxylon e sugerindo idade triássica para o "Arenito Areado". Restos de macrovegetais, possivelmente gimnospermas, provenientes dos folhelhos negros da região de Presidente Olegário foram posteriormente reportados (Scorza \& Santos, 1955; Barbosa, 1965).

Revisões subsequentes (Duarte, 1968, 1985b, 1997) identificaram diversas gimnospermas e angiospermas nos folhelhos (Tabela 1), incluindo coníferas dos gêneros Brachyphyllum e Podozamites, ninfeáceas aquáticas do gênero Nymphaeites e poáceas endêmicas da espécie Paraleptaspis varjensis. Folíolos de Podozamites (Fig.9a) são preservadas como lâminas lanceoladas, isoladas ou semiarticuldas, paralelinérvias, com margem inteira, nervuras delgadas e numerosas (Duarte, 1997, p. 498). Já folhas de cf. Paraleptaspis (Fig. 9b-c) ocorrem como impressões, carbonificadas ou não, com nervura primária destacada, nervuras secundárias proeminentes e separadas por menos de $1 \mathrm{~mm}$ de distância e com numerosas nervuras terciárias interpostas (Duarte, 1997).

As interpretações prévias sobre a ocorrência de Araucarioxylon e a idade triássica do Grupo Areado não se mantiveram. De fato, os táxons descritos por Duarte (1997) são registradas no Aptiano-Albiano da Bacia do Araripe (Duarte, 1985a). Em termos bioestratinômicos, os espécimes vegetais, raros, desarticulados e incompletos, são elementos alóctones ou para-autóctones do ambiente deposicional.

Tabela 1. Macrovegetais da Formação Quiricó, BarremianoAptiano da Bacia Sanfranciscana (Duarte, 1997).

Gymnospermae
Coniferophyta
Brachyphyllaceae
Brachyphyllum obesum Heer, 1881
Podozamitaceae
Podozamites lanceolatus (L. et H.) Sch., 1870
Angiospermae
Nymphaeales
Nymphaeaceae
Nymphaeites choffatii (Sap.) Teixeira, 1947
Poales $\quad$ Poaceae
Paraleptaspis varjensis Duarte, 1997



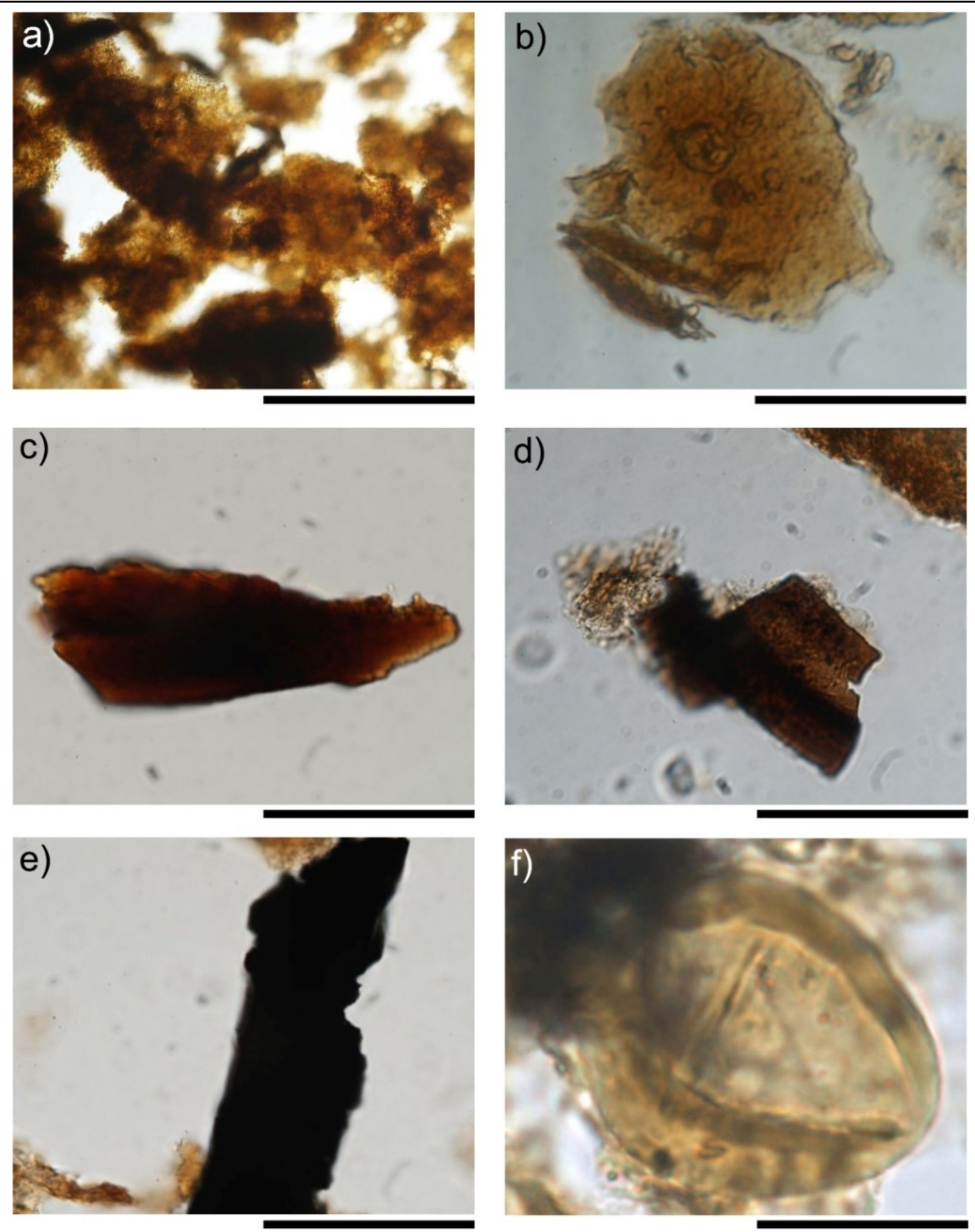

Figura 8. Matéria orgânica, fitoclastos e palinomorfos do Grupo Areado (Formação Quiricó), região de Presidente Olegário: a) matéria orgânica particulada; $\boldsymbol{b}$ ) fitoclasto não opaco não bioestruturado; $c$ ) fitoclasto opaco; d) fitoclasto não opaco bioestruturado estriado; $\boldsymbol{e})$ fitoclasto não opaco bioestruturado; f) grão de pólen Classopollis. Barra de escala única para A e $D=100 \mu \mathrm{m} ; B-C$ e E =50 $\mu \mathrm{m} ; F=20 \mu \mathrm{m}$. Extraído de Fragoso (2011) - reproduzido com permissão.

Para a Bacia de Fonseca, Fanton (2013) contou 33 morfoespécies de dicotiledôneas com base em levantamento da literatura, distribuídos em 18 famílias (Fig. 9d). A Bacia de Gandarela tem diversidade menor, com 11 famílias, incluindo uma pteridófita. A Bacia Juatuba é rica em impressões de folhas de Fabaceae (Fig. 9e) e Melastomataceae (Fonseca \& Costa, 1971; Fragoso et al., 2008).

\subsection{Microfósseis marinhos}

A descoberta de microfósseis exclusivamente marinhos para o Grupo Areado, no início dos anos de 1990, tem gerado debates sobre o ambiente deposicional de alguns de seus estratos, tidos até aquele momento como estritamente continentais. Kattah (1991) e Kattah \& Koutsoukos (1992) relataram a presença de dinoflagelados, radiolários e 
possíveis acritarcos em silexito da Formação Três Barras (sensu Sgarbi et al., 2001), na região de Presidente Olegário (Fig. 10). Tais ocorrências, associadas aos dados sedimentológicos, foram interpretadas como indicativas de um ambiente de plataforma restrita (Kattah, 1992) ou marinho marginal transicional (Castro, 1996).

Estudos posteriores (Pessagno Jr. \& Dias-Brito, 1996; Dias-Brito et al., 1999) registraram a presença de até oito gêneros de radiolários dos grupos Nasselaria e Spumellaria (Tabela 2), além de espículas de esponjas e carapaças de foraminíferos. Os dados corroboram a origem destes microfósseis a partir do Oceano Pacífico, depositados em um ambiente nerítico ou oceânico (Arai, 1999; Dias-Brito
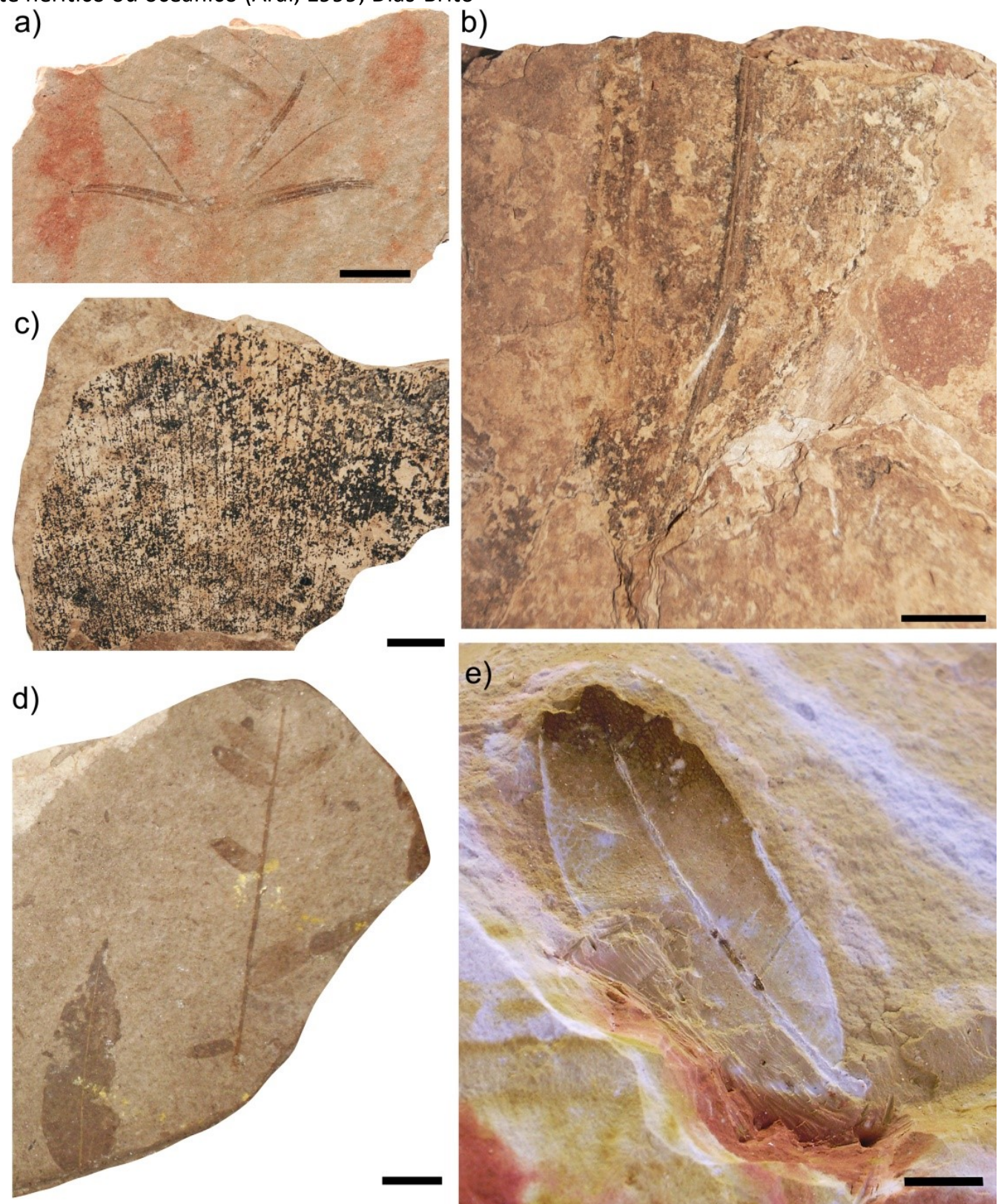

Figura 9. Vegetais fósseis de distintas bacias sedimentares do Cráton do São Francisco. Bacia Sanfranciscana: a) folíolos de Podozamites; b) cf. Paraleptaspis, lâmina foliar incompleta; c) cf. Paraleptaspis, detalhe da venação. Bacia de Fonseca: d) folhas de Fabaceae. Bacia Juatuba: e) folha de dicotiledônea. Escala $a=10 \mathrm{~mm} ; b=10 \mathrm{~mm} ; c=5 \mathrm{~mm} ; d=20 \mathrm{~mm} ; e=5 \mathrm{~mm}$. 
Tabela 2. Microfósseis marinhos do Barremiano-Aptiano da Formação Três Barras (Dias-Brito et al., 1999).

Rhizaria
Radiolaria
Nasselaria
$\quad$ Parvicingula Pessagno, 1977
Caneta spp.
Sethocapsa sp.
Podobursa sp.
Spumellaria
Lanubus ? sp.
Orbiculiforma sp.
Archaeocenosphaera sp.
Noviforemanella aff. hipposiderica (Foreman, 1977)
Spumellariina indet.
Foraminifera
Foraminifera indet.
Globigerinelloides Cushman \& Ten Dam 1948

Como discutido por outros autores (Sgarbi et al., 2001), a controvérsia sobre a origem de tais depósitos está associada basicamente à dificuldade de conciliar os dados sedimentológicos e paleogeográficos, que sugerem um ambiente deposicional raso para o Grupo Areado, delimitado a oeste pelo Arco do Alto Paranaíba, com a ocorrência de fósseis marinhos restritos a uma área sem traços adicionais de conexão com as possíveis fontes oceânicas. Pessagno et al. (1997) sugeriu a existência de um aulacógeno na região, que pudesse introduzir elementos do proto-Pacífico na região central do Cráton do São Francisco no Eocretáceo. No entanto, evidências geológicas ainda são necessárias para dirimir 0 paradoxo sedimentológico/paleogeográfico criado pela hipótese do mar epicontinental sobre o Cráton do São Francisco durante o Cretáceo.

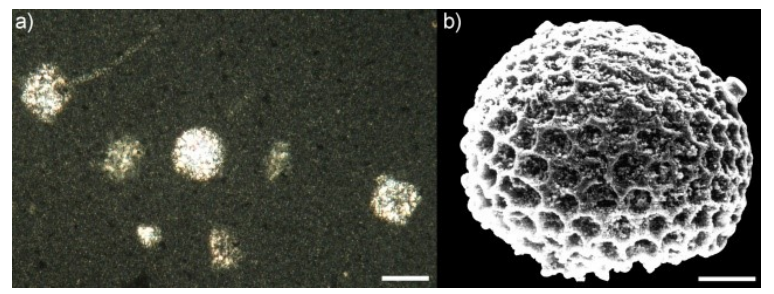

Figura 10. Silexito da região de Galena (Formação Três Barras) em a) seção delgada, sob luz polarizada, mostrando restos de microfósseis marinhos; b) fotomicrografia de varredura do radiolário Archaeocenosphaera (retirado de Dias-Brito et al., 1999). Escala $a=200 \mu \mathrm{m} ; b=50 \mu \mathrm{m}$

\subsection{Metazoários neoproterozoicos}

Warren et al. (2014) reportaram a ocorrência de dois táxons de metazoários típicos do Ediacarano em calcário trombolítico da Formação Sete Lagoas (Tabela 3), na região de Januária (norte de Minas Gerais). O registro inclui o gênero Cloudina, preservada como tubos milimétricos, transversalmente elípticos a circulares (Fig. 11), e o cnidário cifozoário Corumbella werneri, além de bioturbações do gênero Palaeophycus e um tipo bilateral lobado possivelmente referido a Archaeonassa.

Considerando achados anteriores para rochas do pré-cambriano no Cráton do São Francisco, possíveis bioturbações do gênero Skolithos foram preliminarmente relatadas para a Formação Salinas do Grupo Macaúbas (Uhlein et al., 2010). Esta descoberta ainda aguarda estudos mais detalhados para confirmação.

O registro inequívoco de Cloudina e Corumbella adicionam dados importantes sobre a cronoestratigrafia das rochas do Grupo Bambuí, já que o primeiro gênero tem ampla distribuição geográfica e é considerado um fóssil guia para o final do Ediacarano (Grant, 1990; Gaucher \& Germs, 2010). Essa hipótese abre maiores possibilidades para a descoberta de 'vendobiontes' no Grupo Bambuí, como os recentemente reportados no "Arenito Contra Fogo" da Bacia Jaibaras, noroeste do Ceará (Barroso et al., 2014).

\subsection{Artrópodes}

Microcrustáceos têm sido mencionados desde a década de 1960 na Bacia Sanfranciscana. Barbosa (1965) e Barbosa et al. (1970) mencionaram ostracodes Cyprididae, Darwinulidae e Candonidae, descoberta posteriormente confirmada e com adição do registro de Ilyocyprididae e Cytheroidea (Sgarbi, 1989; Barbosa et al., 1997; Sgarbi, 1997; Delicio et al., 1998; do Carmo et al., 2004). Atualmente, cerca de nove gêneros são conhecidos na bacia (Fig. 12; Tabela 3), todos das regiões de João Pinheiro e Carmo do Paranaíba. Do Carmo et al. (2004) correlacionaram as ocorrências da Bacia Sanfranciscana com registros barremianos da Argentina, incluindo estratos da Bacia Neuquina e Grupo Chubut.

Todos os táxons registrados até o momento são típicos de ambientes não marinhos, em consonância com os dados sedimentológicos. Novos espécimes, ainda em estudo, foram descobertos no norte de Minas Gerais durante o mapeamento da Folha Ibiaí (Knauer et al., 2013; Vieira et al., 2015), o que poderá auxiliar nos estudos de correlação bioestratigráfica. 

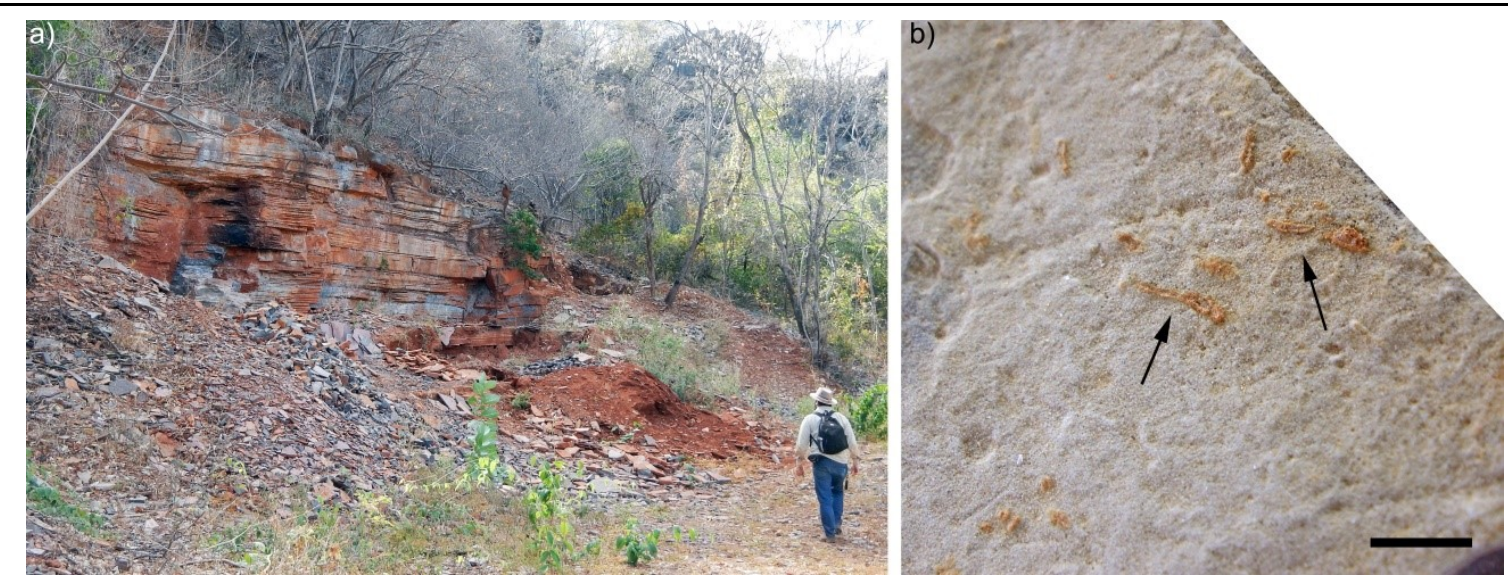

Figura 11. Bacia Bambuí: a) visão geral de um afloramento de calcário da Formação Sete Lagoas, na região de Januária; b) fragmentos de Cloudina. Escala $=5 \mathrm{~mm}$.

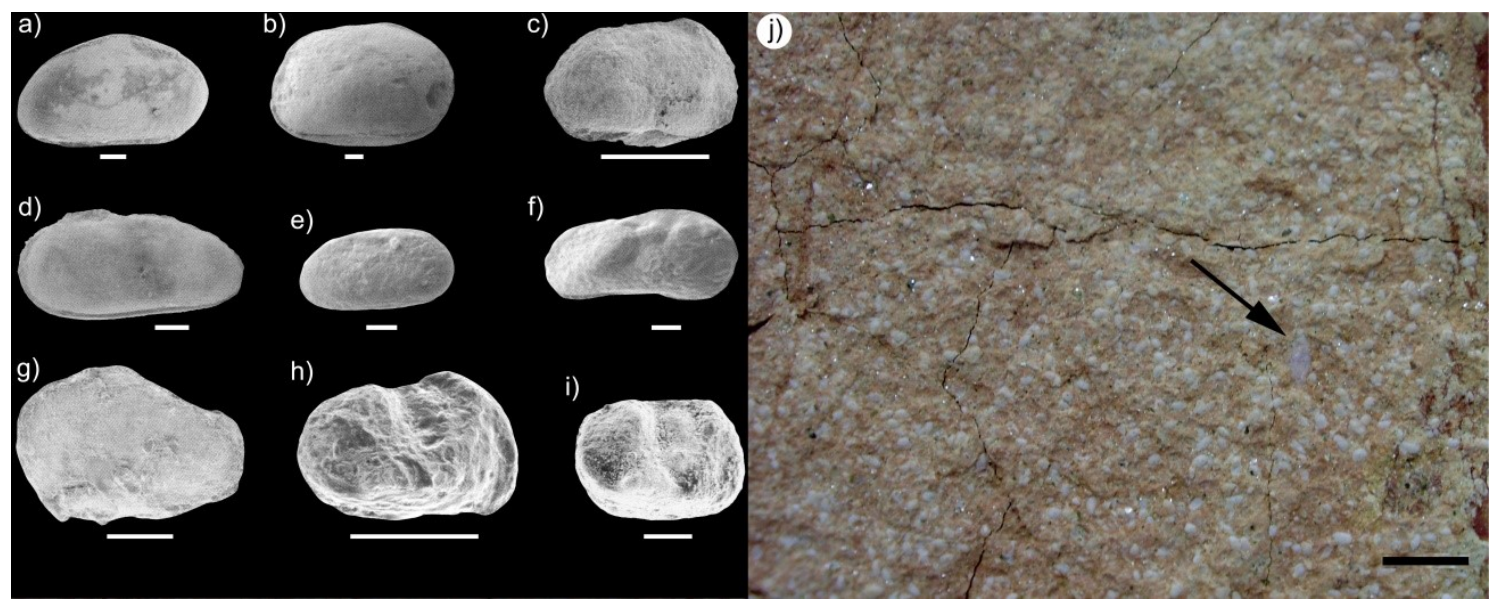

Figura 12. Ostracodes registrados na porção sul da Bacia Sanfranciscana (Grupo Areado, Sub-bacia Abaeté), mostrando: a) Harbinia symmetrica?; b) Brasacypris; c) Wolburgiopsis plastica; d) Darwinula; e) Darwinula estágio A-3; f) llyocypris; g) Cypridea; $\boldsymbol{h}$ ) Bisulcocypridea?; i) Wolburgiopsis chinamuertensis; em vista lateral direita (exceto 'e' e ' $g$ '); Fotomicrografias (a-i) retiradas de Do Carmo et al. (2004); j) amostra de siltito da região de Carmo do Paranaiba com carapaças de ostracodes e um fragmento de "conchostráceo" (seta). Escala $a-i=100 \mu \mathrm{m} ; j=5 \mathrm{~mm}$.

"Conchostráceos" também ocorrem no Grupo Areado, e incluem representantes de Spinicaudata (Fig. 13, Tabela 3; Barbosa et al., 1970; Cardoso, 1971; Delicio et al., 1998). Os gêneros registrados, Cyzicus e Palaeolimnadiopsis, são de água doce e ocorrem nos pacotes superiores aos de Dastilbe, na região de Carmo do Paranaíba, São Gonçalo do Abaeté e João Pinheiro. A taxonomia de Cyzicus é problemática, por englobar espécies do Paleozoico ao Recente (dependendo dos critérios de classificação adotados), por isso sua ocorrência em estratos cretáceos deve ser vista com cautela (Rohn \& Cavalheiro, 1996; Gallego \& Martins-Neto, 2006). Rohn \& Cavalheiro (1996) forneceram um arcabouço bioestratigráfico de correlação com base em "conchostráceos" para o Mesozoico brasileiro. Neste caso, os táxons da Bacia Sanfranciscana podem estar correlacionados às ocorrências do Aptiano (Andar Alagoas) da Bacia do Araripe.

Registros adicionais de artrópodes na Bacia Sanfranciscana incluem Saucrolus silvai Santos (1971), do Cretáceo do Grupo Areado, e os icnotáxons Isopodichnus e Diplichnites, registrados nas fácies glacio-lacustres paleozoicas do Grupo Santa Fé (Campos \& Dardenne, 2002).

A espécie $S$. silvai foi inicialmente tratada como um crustáceo indeterminado, mas posteriormente interpretada como uma larva de inseto aquático da ordem Coleoptera (Martins-Neto, 1996) e depois como um Heteroptera da família Naucoridae (Martins-Neto, 2001; Popov \& Bechley, 2007).

Alguns espécimes previamente identificados como Diplichnites no Grupo Santa Fé são representados por pistas de traços duplos, retilíneos ou ligeiramente curvos, paralelos, com 2-4 $\mathrm{mm}$ de largura cada e distantes entre si 1-4 mm (Fig. 14; ver também Campos \& Dardenne, 1994). Não há indício de segmentação dos traços, embora suas margens sejam irregulares, podendo representar um resquício da impressão dos pódios ou artefato de preservação. As características citadas acima são mais compatíveis com as do gênero Diplopodichnus (Brady, 1947; Buatois et al., 1998), táxon registrado 
em estratos cronocorrelatos de outras bacias sedimentares brasileiras (Balistieri et al., 2002; Tassi, 2010). Os traços típicos deste gênero são considerados variações preservacionais de outros tipos de icnofósseis produzidos por artrópodes, como Cruziana e Diplichnites, podendo então ser atribuídos minimamente a trilobitas, "miriápodes" ou "crustáceos" (Johnson et al., 1994; Keighley \& Pickerill, 1996; Buatois et al., 1998).

Tabela 3. Metazoários fósseis não vertebrados do Cráton do São Francisco (MG), do Proterozoico ao Mesozoico.

\begin{tabular}{|c|c|c|}
\hline TAXON & ESTRATIGRAFIA & IDADE \\
\hline \multicolumn{3}{|l|}{ Metazoa } \\
\hline \multicolumn{3}{|l|}{ Metazoa indet. } \\
\hline Cloudina sp. $^{1}$ & Formação Sete Lagoas & Ediacarano \\
\hline \multicolumn{3}{|l|}{ Porifera } \\
\hline Porifera indet. ${ }^{2}$ & Formação Três Barras & Barremiano-Aptiano \\
\hline \multicolumn{3}{|l|}{ Cnidaria } \\
\hline \multicolumn{3}{|l|}{ Scyphozoa } \\
\hline Corumbella werneri Hahn et al., $1982^{1}$ & Formação Sete Lagoas & Ediacarano \\
\hline \multicolumn{3}{|l|}{ Arthropoda } \\
\hline \multicolumn{3}{|l|}{ Insecta } \\
\hline \multicolumn{3}{|l|}{ Heteroptera } \\
\hline Saucrolus silvai Santos, $1971^{3}$ & Formação Quiricó & Barremiano-Aptiano \\
\hline \multicolumn{3}{|l|}{ 'Crustacea' } \\
\hline \multicolumn{3}{|l|}{ Ostracoda $a^{4,5}$} \\
\hline \multicolumn{3}{|l|}{ Cypridacea indet. } \\
\hline \multicolumn{3}{|l|}{ Cyprididae } \\
\hline Harbinia sp. 1 & Formação Quiricó & Barremiano-Aptiano \\
\hline Brasacypris ovum? Krömmelbein, 1965 & Formação Quiricó & Barremiano-Aptiano \\
\hline Brasacypris sp. 1 & Formação Quiricó & Barremiano-Aptiano \\
\hline Heterocypris Claus, 1892 & Formação Quiricó & Barremiano-Aptiano \\
\hline \multicolumn{3}{|l|}{ Ilyocyprididae } \\
\hline Ilyocypris sp. 1 & Formação Quiricó & Barremiano-Aptiano \\
\hline Cypridea sp. 1 & Formação Quiricó & Barremiano-Aptiano \\
\hline Bisulcocypridea? sp. 1 & Formação Quiricó & Barremiano-Aptiano \\
\hline \multicolumn{3}{|l|}{ Darwinulidae } \\
\hline Darwinula martinsi Silva, 1978 & Formação Quiricó & Barremiano-Aptiano \\
\hline Darwinula sp. & Formação Quiricó & Barremiano-Aptiano \\
\hline \multicolumn{3}{|l|}{ Cytheroidea } \\
\hline Wolburgiopsis chinamuertensis (Musacchio, 1970) & Formação Quiricó & Barremiano-Aptiano \\
\hline \multicolumn{3}{|l|}{ Candonidae } \\
\hline Candonopsis Vávra, 1891 & Formação Quiricó & Barremiano-Aptiano \\
\hline \multicolumn{3}{|l|}{ Spinicaudata ${ }^{6,7}$} \\
\hline Cyzicus abaetensis (Cardoso, 1971) & Formação Quiricó & Barremiano-Aptiano \\
\hline Cyzicus cf. barbosai (Almeida, 1950) & Formação Quiricó & Barremiano-Aptiano \\
\hline Cyzicus sp. & Formação Quiricó & Barremiano-Aptiano \\
\hline Palaeolimnadiopsis freybergi Cardoso, 1971 & Formação Quiricó & Barremiano-Aptiano \\
\hline Palaeolimnadiopsis cf. reali (Teixeira, 1960) & Formação Quiricó & Barremiano-Aptiano \\
\hline
\end{tabular}

a)

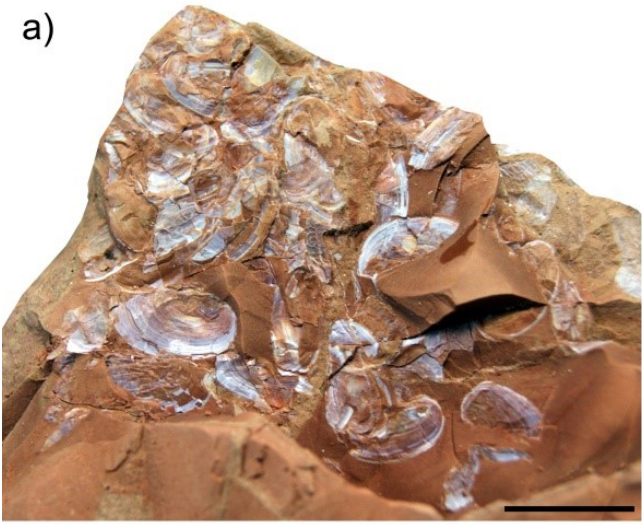

b)

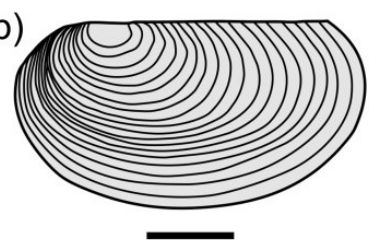

d)

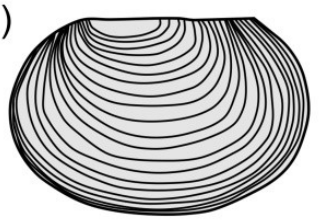

C)

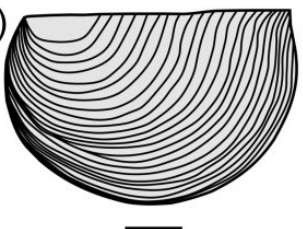

e)

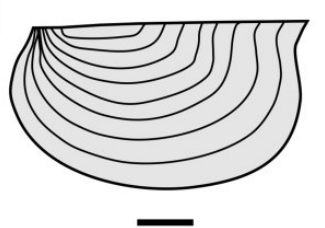

Figura 13. Artrópodes da Bacia Sanfranciscana: a) "conchostráceos" da região de São Gonçalo do Abaeté preservados em pelito avermelhado; valvas esquerdas de b) (yzicus abaetensis; c) Cyzicus barbosai; d) Palaeolimnadiopsis freybergi; e) Palaeolimnadiopsis cf. reali, redesenhados a partir de Cardoso (1971). Barra de escala $a=1 \mathrm{~cm}, b, d=1 \mathrm{~mm} ; c=3 \mathrm{~mm} ; e=5 \mathrm{~mm}$. 


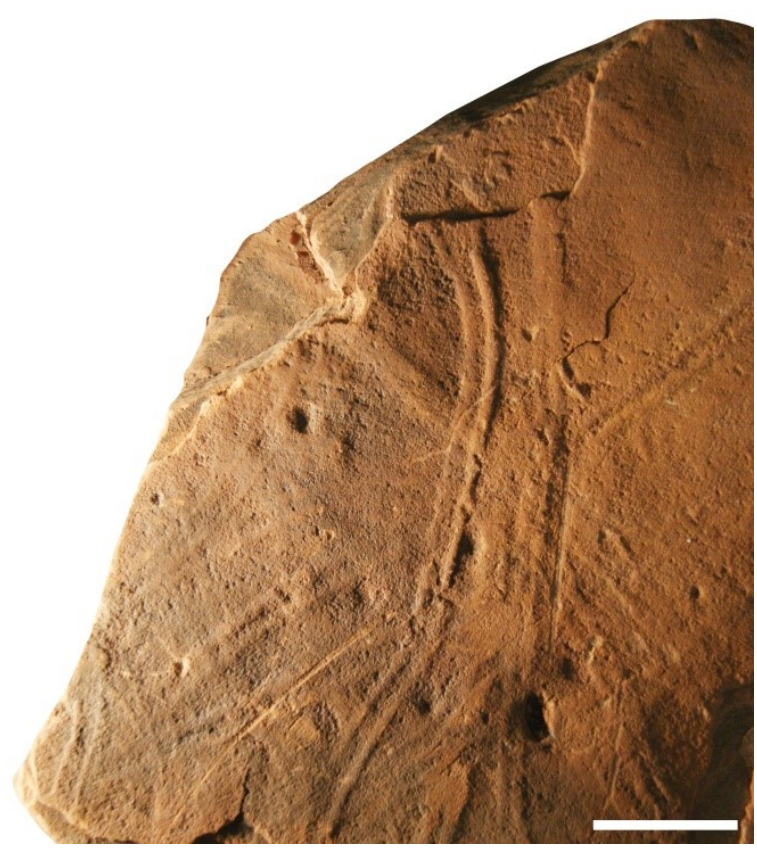

Figura 14. Icnofósseis do gênero Diplopodichnus, proveniente do Permo-Carbonífero do Grupo Santa Fé. Escala $=3 \mathrm{~cm}$

Como discutido por Campos \& Dardenne (1994), os sedimentos do Membro Brejo do Arroz, no Grupo Santa Fé, onde os icnofósseis foram registrados, são de origem glacial lacustre (continental), o que descarta a possibilidade de terem sido produzidos por trilobitas. Artrópodes registrados em fácies de água doce e com possível afinidade com "miriápodes" (e.g. kampecarídeos) ocorrem somente até o Eodevoniano (Almond, 1985; Shear \& Edgecombe, 2010), o que é incompatível com a idade dos estratos paleozoicos da Bacia Sanfranciscana (Campos \& Dardenne, 2002; Brandt \& Ernesto, 2006). Estruturas semelhantes às bioturbações aqui referidas como Diplopodichnus, preservadas nos varvitos de Itu (Subgrupo Itararé, Bacia do Paraná), foram atribuídas a "crustáceos" (Fernandes et al., 1987), hipótese também seguida neste trabalho para os icnofósseis do Grupo Santa Fé.

Com relação aos registros cenozoicos, diversas famílias de insetos foram registradas na Bacia de Fonseca, incluindo espécies das ordens Blattoptera (baratas), Isoptera (cupins), Coleoptera (besouros), Hymenoptera (formigas) e Auchenorrhyncha (cigarras) (Martins Neto, 2005).

\subsection{Vertebrados}

A descoberta de peixes actinopterígios do gênero Dastilbe por Santos (in Scorza \& Santos, 1955), em folhelhos da região de Presidente Olegário (Fig. 15a), é o marco inicial do estudo sistemático de fósseis da Bacia Sanfranciscana. Inicialmente, os materiais provenientes desta localidade foram descritos como uma nova espécie, D. moraesi (Tabela 4). Embora não universalmente aceito (Ribeiro et al., 2005), revisões recentes têm tratado todas as espécies válidas desse gênero como sinônimas de $D$. crandalli (Dietze, 2007; Brito \& Amaral, 2008). Neste trabalho será mantido o nome original, para fins de registro. O gênero em questão é conhecido principalmente na Bacia do Araripe, mas com representantes nas bacias de São Luís-Grajaú, Pernambuco-Paraíba, Sergipe-Alagoas e na Guiné Equatorial (Brito \& Amaral, 2008). Um possível registro na Formação Marizal (Bacia do Tucano) foi interpretado como uma espécie distinta, Nanaichthys longipinnus Amaral \& Brito (2012).
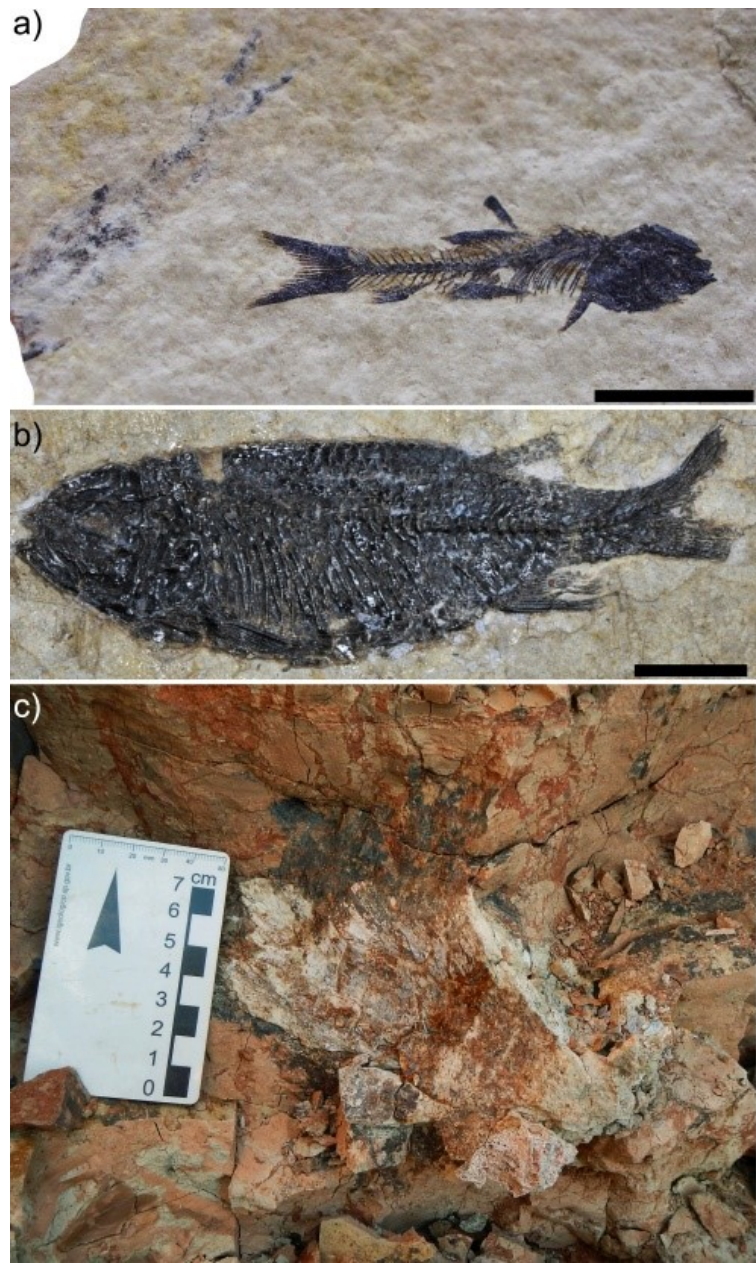

Figura 15. Exemplos de peixes fósseis da Bacia Sanfranciscana: a) espécime de Dastilbe moraesi; b) holótipo de Laeliichthys ancestralis (foto: Valéria Gallo); c) espécime incompleto de Mawsonia. Escala $a, b=1 \mathrm{~cm}$.

Outro registro significativo trata-se do celacantiforme Mawsonia, descoberto nos pelitos da Formação Quiricó (Carvalho et al., 1995), na região de João Pinheiro (Fig. 15c). O gênero é amplamente distribuído, com registros nas bacias do Recôncavo, Tucano, Almada, Sergipe-Alagoas, Araripe, Iguatu e São Luís-Grajaú (Carvalho \& Maisey, 2008). Sua taxonomia é controversa, com propostas incluindo a identificação de duas a seis espécies congêneres 
(Gallo et al., 2010). Carvalho \& Maisey (2008) publicaram uma descrição anatômica detalhada dos restos de celacantiformes da Bacia Sanfranciscana, concluindo que a espécie aí encontrada é distinta de M. tegamensis, do norte da África, e sugerindo um padrão vicariante para a distribuição biogeográfica destes táxons.

Outros registros ainda não formalmente descritos de peixes fósseis da Bacia Franciscana incluem espinhos cefálicos e de nadadeiras associados a Hybodontiformes (Chondrichthyes), vértebras de Amiidae e escamas de semionotiformes (Machado, 2004; Carvalho \& Maisey, 2008).

Vertebrados terrestres eram conhecidos até recentemente apenas por pegadas de dinossauros ornitísquios e terópodes descobertas em seções eólicas (Formação Três Barras) da região de São Gonçalo do Abaeté (Fig. 16, Tabela 4; Carvalho \& Kattah, 1998). Recentemente, restos de dinossauros têm sido coletados em rochas da Formação Quiricó, em diversas localidades da Bacia Sanfranciscana em Minas Gerais.

Zaher et al. (2011) descreveram o titanossauro Tapuiasaurus macedoi, coletado na região de
Coração de Jesus. O holótipo desta espécie e todo o material associado são os primeiros fósseis de vertebrados do extremo norte de Minas Gerais. A relevância do achado reside não apenas na qualidade do material preservado (Fig. 17a) - o crânio de $T$. macedoi é um dos mais completos até o momento para titanossauros - mas também por corroborar o potencial paleontológico da Bacia e as perspectivas de estudos biogeográficos, sedimentológicos e bioestratigráficos.

Apontado pelos autores da descoberta como filogeneticamente próximo a Rapetosaurus (Fig. 17b), de Madagascar, dentro da família Nemegtosauridae, T. macedoi seria o mais antigo membro do grupo informalmente chamado de "titanossauros avançados" (Zaher et al., 2011). A posição derivada da espécie (Fig. 17c-e) foi confirmada por estudos independentes (Carballido \& Sander, 2013; Lacovara et al., 2014; Poropat et al., 2015). Autores, no entanto, aventaram a possibilidade de $T$. macedoi estar mais próximo de Diamantinasaurus, coletado na Austrália, ou como grupo-irmão de Saltasauridae, num cenário em que Nemegtosauridae seria possivelmente parafilético (Lacovara et al., 2014; Poropat et al., 2015).

Tabela 4. Vertebrados fósseis do Barremiano-Aptiano da Bacia Sanfranciscana (MG)

\begin{tabular}{|c|c|}
\hline TAXON & LITOESTRATIGRAFIA \\
\hline \multicolumn{2}{|l|}{ Metazoa (cont.) } \\
\hline \multicolumn{2}{|l|}{ Vertebrata } \\
\hline \multicolumn{2}{|l|}{ Chondrichthyes } \\
\hline \multicolumn{2}{|l|}{ Hybodontiformes } \\
\hline Hybodontiformes indet. ${ }^{1}$ & Formação Quiricó \\
\hline \multicolumn{2}{|l|}{ Osteichthyes } \\
\hline \multicolumn{2}{|l|}{ Actinopterygii } \\
\hline \multicolumn{2}{|l|}{ Semionotiformes } \\
\hline Semionotiformes indet. ${ }^{1}$ & Formação Quiricó \\
\hline \multicolumn{2}{|l|}{ Amiiformes } \\
\hline Amiidae indet. ${ }^{1}$ & Formação Quiricó \\
\hline \multicolumn{2}{|l|}{ Gonorynchiformes } \\
\hline Dastilbe moraesi Santos, $1955^{2}$ & Formação Quiricó \\
\hline \multicolumn{2}{|l|}{ Osteoglossiformes } \\
\hline Laeliichthys ancestralis Santos, $1985^{3}$ & Formação Quiricó \\
\hline \multicolumn{2}{|l|}{ Sarcopterygii } \\
\hline \multicolumn{2}{|l|}{ Coelacanthiformes } \\
\hline Mawsonia gigas Woodward, $1907^{1}$ & Formação Quiricó \\
\hline \multicolumn{2}{|l|}{ Dinosauria } \\
\hline \multicolumn{2}{|l|}{ Sauropoda } \\
\hline Tapuiasaurus macedoi Zaher et al., $2010^{4}$ & Formação Quiricó \\
\hline \multicolumn{2}{|l|}{ Theropoda } \\
\hline Theropoda indet. ${ }^{5}$ & Formação Três Barras \\
\hline cf. Dromaeosauridae ${ }^{6,7}$ & Formação Quiricó \\
\hline cf. Abelisauridae ${ }^{6}$ & Formação Quiricó \\
\hline Abelisauroidae indet. ${ }^{4,8}$ & Formação Quiricó \\
\hline Nosauridae $^{9}$ & Formação Quiricó \\
\hline \multicolumn{2}{|l|}{ Ornithischia } \\
\hline Ornithischia indet. ${ }^{5}$ & Formação Três Barras \\
\hline
\end{tabular}


a)

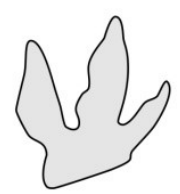

c)

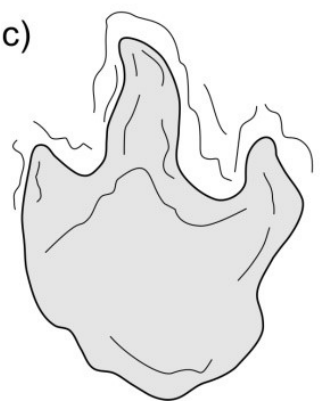

b)

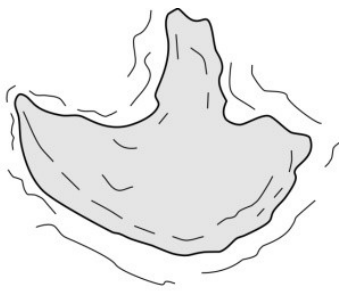

d)

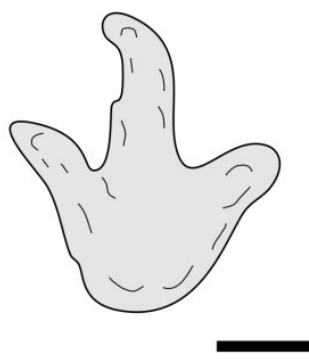

Figura 16. Pegadas de dinossauros do Grupo Areado (Formação Três Barras), atribuídas a terópodes (a, $\boldsymbol{c}, \boldsymbol{d})$ e ornitópode (b). Modificado de Carvalho \& Kattah (1998). Escala $=10 \mathrm{~cm}$.

a)

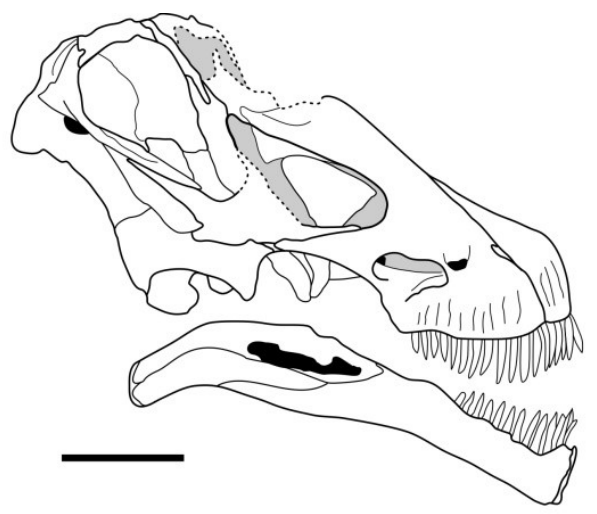

b)

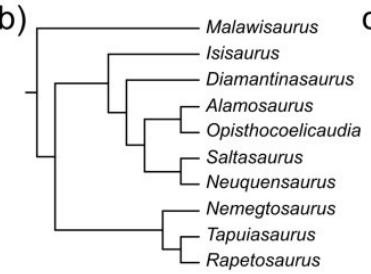

d)

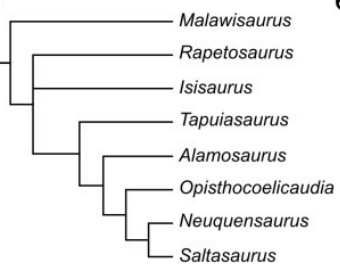

c)

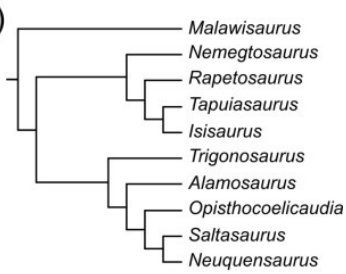

e)

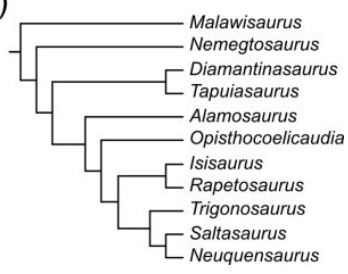

Figura 17. Crânio do titanossauro Tapuiasaurus macedoi (a), em vista lateral direita (modificado de Zaher et al., 2011). Propostas de posicionamento filogenético de T. macedoi segundo: b) Zaher et al. (2011); c) Carballido \& Sander (2013); d) Lacovara et al.

(2014); e) Poropat et al. (2015). Escala $=10 \mathrm{~cm}$.

Silva (2013) descreveu parte do membro posterior direito de um terópode Noasauridae, incluindo a porção distal da tíbia e fíbula, astrágalo, calcâneo, metatarsais I-IV e falanges. Esta família, que engloba táxons da Argentina, África $\mathrm{e}$ Madagascar, Índia e Europa, do Albiano ao Maastrichtiano (Carrano \& Sampson, 2008), já havia sido registrada em estratos cenomanianos da Bacia São Luís, estado do Maranhão (Lindoso et al., 2012).

Outros materiais de dinossauros aguardando descrição detalhada incluem dezenas de fragmentos ósseos isolados, escavados em Lagoa dos Patos e Ibiaí (Vieira et al., 2015) e um crânio relativamente completo de um dinossauro de grande porte também preliminarmente atribuído a Abelisauroidea (Zaher et al., 2011). Completando o registro conhecido até então para vertebrados terrestres, dentes isolados provenientes da Formação Quiricó, no norte de Minas, foram preliminarmente atribuídos a Abelisauridae e Dromaeosauridae (Carvalho et al., 2012; Santucci et al., 2014).

\section{CONSIDERAÇÕES FINAIS}

Com exceção dos microbialitos proterozoicos e dos depósitos cenozoicos, a pequena abundância de fósseis no Cráton do São Francisco é incompatível com a extensão dos depósitos sedimentares aflorantes. Parte deste cenário resulta da falta de programas de prospecção e coleta paleontológica, que têm avançado mais vagarosamente que o conhecimento geológico resultante dos projetos de mapeamento.

Ocorrências fósseis nas seções neoproterozoicas (Criogeniano/Ediacarano) são mundialmente raras. No caso do Grupo Bambuí, apesar da falta de consenso sobre a idade de sua deposição (Babinski et al., 2007; Caxito et al., 2012; Pimentel et al., 2012), a descoberta do gênero Cloudina contribuiu para corroborar os dados geocronológicos que sugerem uma idade ediacarana (Pimentel et al., 2012; Paula-Santos et al., in press).

Na Bacia Sanfranciscana, o Grupo Santa Fé foi datado do Carbonífero-Permiano, enquanto que as seções fossilíferas da porção Mesozoica concordam com 0 intervalo Barremiano-Aptiano. Essa descontinuidade dos depósitos sedimentares mostram hiatos de cerca de 250 milhões de anos entre as biotas neoproterozoicas e paleozoicas e de cerca de 125 milhões de anos (Eocretáceo ao Pleistoceno) para a fauna de vertebrados no Cráton do São Francisco.

A quantidade de material coletado em trabalhos de campo mais recentes (Vieira et al., 2015) sugere um grande potencial paleontológico das coberturas sedimentares do Cráton do São Francisco. 


\section{AGRADECIMENTOS}

Os autores agradecem a Rafael Horta, Pedro Vieira e Angelo dos Santos pela ajuda em diversos trabalhos de campo na Bacia Sanfranciscana. Agradecemos a Valéria Gallo (UERJ, Rio de Janeiro), pela foto do holótipo de Laeliichthys, Daniel Fragoso (Petrobrás, Rio de Janeiro), pelas fotos da Figura 8, e também a Lucas Warren (UNESP, Rio Claro), Guilherme Knauer (UFMG, Belo Horizonte) e Alexandre Uhlein (UFMG, Belo Horizonte), que forneceram informações que enriqueceram algumas discussões apresentadas neste trabalho. Rosemarie Rohn (UNESP, Rio Claro) e Max Langer (USP, Ribeirão Preto) revisaram versões preliminares do manuscrito. Financiado pela FAPEMIG (APQ-0051713).

\section{REFERÊNCIAS BIBLIOGRÁFICAS}

Aitken, J.D., 1967. Classification and environmental significance of cryptalgal limestones and dolomites, with illustrations from the Cambrian and Ordovician of southwestern Alberta. Journal of Sedimentary Research 37, 1163-1178.

Alkmin, F.F., 2004. O que faz de um cráton um cráton? O Cráton do São Francisco e as revelações almeidianas ao delimitá-lo, In: Mantesso-Neto, V., Bartorelli, A., Carneiro, C.D.R., Neves, B.B.B. (Eds.), Geologia do Continente Sul Americano. Evolução da obra de Fernando Marques de Almeida. Beca, São Paulo, pp. 17-35.

Alkmin, F.F., Marshak, S., 1998. Transamazonian orogeny in the southern São Francisco craton region, Minas Gerais, Brazil: evidence for Paleoproterozoic Collision and collapse in the Quadrilátero Ferrífero. Precambrian Research 90, 29-58.

Alkmin, F.F., Martins-Neto, M.A., 2001. A Bacia Intracratônica do São Francisco: arcabouço estrutural e cenários evolutivos, In Pinto, C.P., Martins-Neto, M.A. (Eds.), Bacia do São Francisco: Geologia e Recursos Naturais. SBG, Belo Horizonte, pp. 9-30.

Almeida, F.F.M., 1977. O Cráton do São Francisco. Revista Brasileira de Geociências 7, 349-364.

Almond, J.E., 1985. The Silurian-Devonian fossil record of the Myriapoda. Philosophical Transactions of the Royal Society of London B 309, 227-237.

Alvarenga, C.J.S., 1978. Geologia e Prospecção Geoquímica dos Grupos Bambuí e Paranoá na Serra de São Domingos, MG. Tese de Mestrado, Universidade de Brasília. 130 pp.

Alvarenga, C.J.S., Dardenne, M.A., Vieira, L.C., Martinho, C.T., Guimarães, E.M., Santos, R.V., Santana, R.O., 2012 Estratigrafia da borda ocidental da Bacia do São Francisco. Boletim de Geociências da PETROBRÁs 20, 145-164.

Amaral, C.R.L., 2010. Análise Paleogegráfica do Intervalo Aptiano/Albiano do Gondwana Ocidental, com base na Distribuição da Família Chanidae. Tese de Mestrado, Universidade do Estado do Rio de Janeiro. 95 pp.

Amaral, C.R.L., Brito, P.M., 2012. A New Chanidae (Ostariophysii: Gonorynchiformes) from the Cretaceous of Brazil with Affinities to Laurasian Gonorynchiforms from Spain. PlosOne 7, 1-9.

Arai, M., 1999. A transgressão marinha Mesocretácea: sua implicação no paradigma da reconstituição paleogeográfica do Cretáceo no Brasil In: 5o Simpósio sobre o Cretáceo do Brasil, Boletim, Serra Negra, p. 577-582.
Arai, M., 2009. Paleogeografia do Atlântico Sul no Aptiano: um novo modelo a partir de dados micropaleontológicos recentes. Boletim de Geociências da Petrobrás 17, 331-351.

Arai, M., Dino, R., Milhomem, P.S., Sgarbi, G.N.C., 1995. Micropaleontologia da Formação Areado, Cretáceo da Bacia Sanfranciscana: estudo dos ostracodes e palinologia. In: XIV Congresso Brasileiro de Paleontologia, Atas, Uberaba, p. 1-2.

Awramik, S.M., 1990. Stromatolites, In: Briggs, D.E.G., Crowther, P.R. (Eds.), Palaeobiology: A Synthesis. Blackwell Science, Oxford, pp. 336-340.

Babinski, M., 1993. Idades isocrônicas $\mathrm{Pb} / \mathrm{Pb}$ e geoquímica isotópica de $\mathrm{Pb}$ das rochas carbonáticas do Grupo Bambuí, na porção sul da Bacia do São Francisco. Tese de Doutorado, Universidade de São Paulo. 133 pp.

Babinski, M., Chemale Jr., F., Van Schmus, W.R., 1995. The Pb/Pb age of the Minas Supergroup carbonate rocks, Quadrilátero Ferrífero, Brazil. Precambrian Research 72, 235-245.

Babinski, M., Vieira, L.C., Trindade, R.I.F., 2007. Direct dating of the Sete Lagoas cap carbonate (Bambuí Group, Brazil) and implications for the Neoproterozoic glacial events. Terra Nova 19, 401-406.

Balistieri, P., Netto, R.G., Lavina, E.L.C., 2002. Ichnofauna from the Upper Carboniferous-Lower Permian rhythmites from Mafra, Santa Catarina State, Brazil: ichnotaxonomy. Revista Brasileira de Paleontologia 4, 13-26.

Baptista, M.C., Signorelli, N., Tuller, M.P., Cruz, N.M.C., Brito, D.C., 2010. Ocorrência de acritarcos em rochas metassedimentares dos grupos Bambuí (Neoproterozoico e Vazante (Mesoproterozoico) no oeste de Minas Gerais. In: 45은 Congresso Brasileiro de Geologia, Belém, p. 1004

Barbosa, E.M., Delicio, M.P., Coimbra, J.C., 1997. Conchostracans and ostracodes indicators of paleoenvironment in the Alto Sanfranciscana Basin, Olhos d'Agua Area, Northwest of Minas Gerais state Brazil. In: The First International Conference "Application of Micropaleontology in Environmental Sciences", Tel Aviv, p. 37-38.

Barbosa, O., 1965. Geologia econômica e aplicada a uma parte do Planalto Central brasileiro. In: XIX Congresso Brasileiro de Geologia, Anais, Rio de Janeiro, p. 1-11.

Barbosa, O., Braun, O.P.G., Dyer, R.C., da Cunha, C.A.B.R., 1970. Geologia da região do Triângulo Mineiro. Boletim da Divisão de Fomento da Produção Mineral 136, 1-140.

Barroso, F.R.G., Viana, M.S.S., Lima Filho, M.F., Agostinho, S.M.O., 2014. First Ediacaran fauna occurrence in northeastern Brazil (Jaibaras Basin, ?Ediacaran-Cambrian): preliminary results and regional correlation. Anais da Academia Brasileira de Ciências 86, 1029-1042.

Bittencourt, J.S., Langer, M.C., 2011. Mesozoic dinosaurs from Brazil and their biogeographic implications. Anais da Academia Brasileira de Ciências 83, 23-60.

Bittencourt, J.S., Vasconcelos, A.G., Carmo, F.F., Buchmann, F.S., 2015. Registro paleontológico em caverna desenvolvida em formações ferríferas na Serra do Gandarela, In: Ruchkys, U., Travassos, L.E.P., Rasteiro, M.A., Faria, L.E. (Eds.), Patrimônio Espeleológico em Rochas Ferruginosas: Propostas para sua conservação no Quadrilátero Ferrífero, Minas Gerais. Sociedade Brasileira de Espeleologia, Campinas, pp. 192-206.

Bonde, N., 2008. Osteoglossomorphs of the marine Lower Eocene of Denmark - with remarks on other Eocene taxa and their importance for palaeobiogeography. Geological Society, London, Special Publications 295, 253-310.

Brady, L.F., 1947. Invertebrate tracks from the Coconino Sandstones of Northern Arizona. Journal of Paleontology 21, 466-472. 
Brandt, D., Ernesto, M., 2006. Resultados paleomagnéticos preliminares do Grupo Santa Fé (Paleozoico da Bacia Sanfranciscana): implicações sobre a idade e paleolatitude da sedimentação glacial. Revista Brasileira de Geofísica 24, 199207.

Brito Neves, B.B., Campos Neto, M.C., Fuck, R., 1999. From Rodinia to Western Gondwana: an approach to the Brasiliano/Pan-African cycle and orogenic collage. Episodes 22, 155-199.

Brito, P.M., Amaral, C.R., 2008. An overview of the specific problems of Dastilbe Jordan, 1910 (Gonorynchiformes, Chanidae) from the Lower Cretaceous of western Gondwana, In: Arratia, G., Schultze, H.-P., Wilson, M.V. (Eds.), Mesozoic Fishes 4. Homology and Phylogeny. Verlag Dr. F. Pfeil, Munique, pp. 279-294.

Buatois, L.A., Mangano, M.G., Maples, C.G., Lanier, W., 1998. Ichnology of an Upper Carboniferous fluvio-estuarine paleovalley: the Tonganoxie Sandstone, Buildex Quarry, Eastern Kansas, USA. Journal of Paleontology 72, 152-180.

Campos, J.E.G., Dardenne, M.A., 1994. A Glaciação Neopaleozóica na Porção Meridional da Bacia Sanfranciscana. Revista Brasileira de Geociências 23, 65-76.

Campos, J.E.G., Dardenne, M.A., 1997a. Estratigrafia e Sedimentação da Bacia Sanfranciscana: uma revisão. Revista Brasileira de Geociências 27, 227-240.

Campos, J.E.G., Dardenne, M.A., 1997b. Origem e evolução tectônica da Bacia Sanfranciscana. Revista Brasileira de Geociências 27, 241-252.

Campos, J.E.G., Dardenne, M.A., 2002. Pavimentos estriados do Grupo Santa Fé - Neopaleozóico da Bacia Sanfranciscana, MG, In: Schobbenhaus, C., Campos, D.A., Queiroz, E.T., Winge, M., Berbert-Born, M. (Eds.), Sítios Geológicos e Paleontológicos do Brasil. DNPM CPRM SIGEP, Brasília, pp. 161-164.

Campos, J.E.G., Dardenne, M.A., Freitas-Silva, F.H., MartinsFerreira, M.A.C., 2013. Geologia do Grupo Paranoá na porção externa da Faixa Brasília. Brazilian Journal of Geology 43, 461-476.

Carballido, J.L., Sander, P.M., 2013. Postcranial axial skeleton of Europasaurus holgeri (Dinosauria, Sauropoda) from the Upper Jurassic of Germany: implications for sauropod ontogeny and phylogenetic relationships of basal Macronaria. Journal of Systematic Palaeontology 12, 335-387.

Cardoso, R.N., 1971. Contribuição ao estudo da Formação Areado: estratigrafia e descrição dos filópodos fósseis. Arquivos do Museu de História Natural 1, 9-47.

Carrano, M.T., Sampson, S.D., 2008. The Phylogeny of Ceratosauria. Journal of Systematic Palaeontology 6, 183236.

Cartelle, C., 1994. Tempo Passado. Acesita, Belo Horizonte. 132 $\mathrm{pp}$.

Cartelle, C., 2012. Das grutas à luz. Bicho do Mato, Belo Horizonte. $236 \mathrm{pp}$.

Carvalho, A.B., Zaher, H., da Silva, R.R., Nascimento, P.M., 2012. Análise morfológica dos dentes de terópodes (Dinosauria: Saurischia) da Formação Quiricó, Eocretáceo da Bacia Sanfranciscana, estado de Minas Gerais. In: VIII simpósio Brasileiro de Paleontologia de Vertebrados, Boletim de Resumos, Recife, p. 109.

Carvalho, I.S., Bertolino, L.C., Borghi, L.F., Duarte, L., Carvalho, M.S.S., Cassab, R.C.T., 1994. Range charts of the fossils of the Cretaceous interior basins - The São Francisco Basin, In: Beurlen, G., Campos, D.A., Viviers, M.C. (Eds.), Stratigraphic range of Cretaceous mega- and microfossils of Brazil. UFRJ, Rio de Janeiro, pp. 333-352.
Carvalho, I.S., Kattah, S., 1998. As pegadas fósseis do paleodeserto da Bacia Sanfranciscana (Jurássico SuperiorCretáceo Inferior, Minas Gerais). Anais da Academia Brasileira de Ciências 70, 53-67.

Carvalho, M.S.S., Campos, D.A., Dardenne, M.A., Sgarbi, G.N.C., Campos, J.E.G., Cartelle, C., 1995. Ocorrência de celacantídeo Mawsonia nos sedimentos lacustres da Bacia Sanfranciscana, noroeste do Estado de Minas Gerais. In: XIV Congresso Brasileiro de Paleontologia, Uberaba, p. 35.

Carvalho, M.S.S., Maisey, J.G., 2008. New occurrence of Mawsonia (Sarcopterygii: Actinistia) from the Early Cretaceous of the Sanfranciscana Basin, Minas Gerais, southeastern Brazil. Geological Society Special Publication 295, 109-144.

Cassedanne, J., 1965. Decouverte d'algue dans le calcaire de Bambui (Etat de Minas Gerais, Brésil). Anais da Academia Brasileira de Ciências 37, 79-81.

Cassedanne, J., 1968. Description du biostrome à Collenias de la Mine de Vazante (Minas Gerais). Anais da Academia Brasileira de Ciências 40, 215-225.

Cassedanne, J.P., Cassedanne, J.O., 1978. Les stromatolites globuleux de la Fazenda Serra Virgem (Minas Gerais). Revista Brasileira de Geociências 8, 219-234.

Castro, J.C., 1996. O Cretáceo da porção sul da Bacia Sanfranciscana: uma breve revisão. In: 40 Simpósio sobre o Cretáceo do Brasil, Boletim, Águas de São Pedro, p. 209-211.

Caxito, F.A., Halverson, G.P., Uhlein, A., Stevenson, R., Dias, T.G., Uhlein, G.J., 2012. Marinoan glaciation in east central Brazil. Precambrian Research 200-203, 38-58.

Cloud, P., Dardenne, M.A., 1973. Proterozoic Age of the Bambui Group in Brazil. Bulletin of the Geological Society of America 84, 1673-1676.

CPRM/CODEMIG, 2014. Mapa Geológico do Estado de Minas Gerais. CPRM/CODEMIG.

Cruz, N.M.C., Lopes, J.N., 1992. Microfósseis do Grupo Bambuí. Anais da Academia Brasileira de Ciências 64, 420.

Dardenne, M.A., 2000. The Brasilia Fold Belt, In: Cordani, U.G., Milani, E.J., Thomaz-Filho, A., Campos, D.A. (Eds.), Tectonic Evolution of South America. 31st International Geological Congress, Rio de Janeiro, pp. 231-263.

Dardenne, M.A., 2009. Conophyton de Cabeludo, Grupo Vazante, MG: Construções dolomíticas por ciano-bactérias no Proterozóico, In: Winge, M., Schobbenhaus, C., Souza, C.R.G., Fernandes, A.C.S., Berbert-Born, M., Queiroz, E.T., Campos, D.A. (Eds.), Sítios Geológicos e Paleontológicos do Brasil. DNPM CPRM SIGEP, Brasília, pp. 303-310.

Dardenne, M.A., Campos, J.E.G., Campos Neto, M.C., 2009 Estromatólitos colunares no Sumidouro do córrego Carrapato, Lagamar, MG, In: Winge, M., Schobbenhaus, C., Souza, C.R.G., Fernandes, A.C.S., Berbert-Born, M., Queiroz, E.T., Campos, D.A. (Eds.), Sítios Geológicos e Paleontológicos do Brasil. CPRM/SIGEP, Brasília, pp. 311-320.

Dardenne, M.A., Campos Neto, M.C., 1975. Estromatólitos colunares na Série Minas (MG). Revista Brasileira de Geociências 5, 95-105.

Dardenne, M.A., Melo, S.M.G., Moeri, E., 1972. Conophyton: um fóssil index do Pré-Cambriano no Grupo Bambuí. Ciência e Cultura 24, 199-203.

Davis, S.P., Martill, D.M., 1999. The gonorynchiform fish Dastilbe from the Lower Cretaceous of Brazil. Palaeontology 42, 715740. 
Delicio, M.P., Barbosa, E.M., Coimbra, J.C., Vilella, R.A., 1998 Ocorrência de conchostraceos e ostracodes em sedimentos Pós-Paleozóicos da Bacia do Alto Sanfranciscana, Olhos d'Água, noroeste de Minas Gerais, Brasil. Acta Geologia Leopoldensia 46/47, 13-20.

Dias-Brito, D., Pessagno Jr., E.A., Castro, J.C., 1999. Novas considerações cronoestratigráficas sobro silexito a radiolários do sul da Bacia Sanfranciscana, Brasil, e a ocorrência de foraminíferos planctônicos nestes depósitos. In: 50 Simpósio sobre o Cretáceo do Brasil, Boletim, Rio Claro, p. 567-575.

Dietze, K., 2007. Redescription of Dastilbe crandalli (Chanidae, Euteleostei) from the Early Cretaceous Crato Formation of North-Eastern Brazil. Journal of Vertebrate Paleontology 27, 8-16.

do Carmo, D.A., Tomassi, H.Z., Oliveira, S.B.S.G., 2004. Taxonomia e distribuição estratigráfica dos ostracodes da Formação Quiricó, Grupo Areado (Cretáceo Inferior), Bacia Sanfranciscana, Brasil. Revista Brasileira de Paleontologia 7, 139-149.

Dorr, J.V.N., 1969. Physiographic, Stratigraphic and Structural Development of the Quadrilatero Ferrifero Minas Gerais, Brazil. US Government Printing Office, Washington. 110 pp.

Duarte, L., 1968. Restos vegetais fósseis da Formção Areado. In: XXII Congresso Brasileiro de Geologia, Anais, Belo Horizonte, p. 68.

Duarte, L., 1985a. Vegetais fósseis da Chapada do Araripe, In: Campos, D.A., Ferreira, C.S., Brito, I.M., Viana, C.F. (Eds.), Coletânea de Trabalhos Paleontológicos. DNPM, Rio de Janeiro, pp. 557-563.

Duarte, L., 1985b. Vegetais fósseis da Formação Areado, município de Presidente Olegário, Minas Gerais. In: 9o Congresso Brasileiro de Paleontologia, Resumos, Fortaleza, p. 59.

Duarte, L., 1997. Vegetais do Cretáceo Inferior (Aptiano) da Formação Areado, município de Presidente Olegário, Estado de Minas Gerais. Anais da Academia Brasileira de Ciências 69, 495-503.

Fairchild, T.R., Dardenne, M.A., 1978. First report of a wellpreserved Precambrian microfossils in Brazil (Paraopeba Formation, Bambuí Group, near Brasília). Boletim IG-USP 9, $62-68$

Fairchild, T.R., Sanchez, E.A.M., Pacheco, M.L.A.F., Leme, J.M., 2012. Evolution of Precambrian life in the Brazilian geological record. International Journal of Astrobiology 11, 309-323.

Fairchild, T.R., Subacius, S.M.R., 1986. Microfossils associated with silicified Stratifera undata Komar 1966 from the late Proterozoic Bambuí Group, south-central Brazil. Precambrian Research 33, 323-339.

Fairchild, T.R., Subacius, S.M.R., Karmann, I., 1980. A silicified stromatolitic microflora from the late precambrian of westcentral Brazil and its implications for proterozoic biostratigraphy Boletim IG 11, 33-40.

Fantinel, L.M., Kuchenbecker, M., Alvarenga, C.J.S., Guimarães, E.M., Fairchild, T.R., Rohn, R., Sanches, E.A.M., Dardenne, M.A., 2015. Microbialitos da Formação Sete Lagoas (Grupo Bambuí), Neoproterozoico, em Minas Gerais e Goiás, In: Fairchild, T.R., Rohn, R., Dias-Brito, D. (Eds.), Microbialitos do Brasil do Pré-Cambriano ao Recente: Um Atlas. UNESP, IGCE, UNESPetro, Rio Claro, pp. 168-193.

Fanton, J.C.M., 2013. Reconstruindo as florestas tropicais úmidas do Eoceno-Oligoceno do sudeste do Brasil (bacias de Fonseca e Gandarela, Minas Gerais) com folhas de Facabaceae, Myrtaceae e outras angiospermas: origens da Mata Atlântica.
Tese de Doutorado, Universidade Estadual de Campinas. 310 pp.

Favoreto, J., Rohn, R., Fairchild, T.R., 2011. Microbialitos do Grupo Vazante, Formação Lagamar, Neoproterozoico, na Fazenda Sumaré, município de Lagamar (MG), In: Carvalho, I.S., Srivastava, N.K., Strochschoen Jr, O., Lana, C.C. (Eds.), Paleontologia - Cenários de Vida. Interciência, Rio de Janeiro, pp. 48-56.

Fernandes, A.C.S., Antunes, M.T., Brandão, J.M., Ramos, R.R.C., 2012. O Monstro de Prados e Simão Pires Sardinha: considerações sobre o primeiro relatório de registro de um fóssil brasileiro. Filosofia e História da Biologia 7, 1-22.

Fernandes, A.C.S., Carvalho, I.S., Netto, R.G., 1987. Comentários sobre os traços fósseis do paleolago de Itu, São Paulo. In: 6으 Simpósio Regional de Geologia, Atas, 1, Rio Claro, p. 297-311.

Flügel, E., 2010. Microfacies of carbonate rocks: analysis, interpretation and application, 2 ed ed. Springer, Heidelberg. $984 \mathrm{pp}$.

Fonseca, J.S., Costa, M.T., 1971. Nota preliminar sôbre a ocorrência de vegetais fósseis no vale do Rio Paraopeba, município de Mateus Leme, MG. Revista da Escola de Minas $29,80$.

Fraga, L.M.S., Neves, S.C., Pires, G.L.P., Tibães, A.L., Uhlein, A., 2013. Estromatólitos colunares na base do Grupo Macaúbas, nordeste da Serra do Espinhaço (MG): paleontologia e ambiente de sedimentação. Geonomos 21, 34-43.

Fraga, L.M.S., Neves, S.C., Uhlein, A., Sial, A.N., Pimentel, M.M., Horn, A.H., 2014. C-, Sr-isotope stratigraphy of carbonate rocks from the Southern Espinhaço Ridge, Minas Gerais, southeastern Brazil. Anais da Academia Brasileira de Ciências $86,633-648$

Fragoso, D.G.C., 2011. Geologia da região de Presidente Olegário e evolução tectono-sedimentar do Grupo Areado, Eocretáceo da Bacia Sanfranciscana, Minas Gerais. Tese de Mestrado, Universidade Federal de Minas Gerais. 183 pp.

Fragoso, D.G.C., Gouveia, M.H., Sobral, M.E.G., Meyer, K.E.B., Romano, A.W., 2008. Resultados preliminares sobre a estratigrafia e paleobotânica da Bacia de Juatuba, MG, Brasil. In: XII Simpósio de Paleobotânicos e Palinólogos, Florianópolis, p. 78.

Fragoso, D.G.C., Suckau, G.L., Guerzoni, H.T.G., Sanglard, J.C.D., Faria, P.H., Uhlein, A., 2011a. Folha Presidente Olegário SE.23-Y-B-I - Escala 1:100.000. CODEMIG.

Fragoso, D.G.C., Uhlein, A., Sanglard, J.C.D., Suckau, G.L., Guerzoni, H.T.G., Faria, P.H., 2011b. Geologia dos grupos Bambuí, Areado e Mata da Corda na Folha Presidente Olegário (1:100.000), MG: Registro deposicional do Neoproterozóico ao Neocretáceo da Bacia do São Francisco. Geonomos 19, 28-38.

Frank, H.T., Buchmann, F.S.C., de Lima, L.G., Fornari, M., Caron, F., Lopes, R.P., 2012. Cenozoic vertebrate tunnels in Southern Brazil. Monografias da Sociedade Brasileira de Paleontologia 2, 141-157.

Freyberg, B.v., 1965. Resultado das pesquisas geológicas em Minas Gerais. In: XIX Congresso Brasileiro de Geologia, Anais, Rio de Janeiro, p. 156-211.

Gallego, O.F., Martins-Neto, R.G., 2006. The Brazilian Mesozoic conchostracan faunas: its geological history as an alternative tool for stratigraphic correlations. Geociências 25, 231-239.

Gallo, V., Carvalho, M.S.S., Santos, H.R.S., 2010. New occurrence of +Mawsoniidae (Sarcopterygii, Actinistia) in the Morro do Chaves Formation, Lower Cretaceous of the Sergipe-Alagoas Basin, Northeastern Brazil. Boletim do Museu Paraense Emílio Goeldi de Ciências Naturais 5, 195-205. 
Gaucher, C., Germs, G.J.B., 2010. Skeletonised metazoans and protists, In: Gaucher, C., Sial, A.N., Halverson, G.P., Frimmel, H.E. (Eds.), Neoproterozoic-Cambrian Tectonics, Global Change and Evolution. Elsevier, Amsterdam, pp. 327-338.

Gaucher, C., Sprechmann, P., 2010. Neoproterozoic acritarch evolution, In: Gaucher, C., Sial, A.N., Halverson, G.P., Frimmel, H.E. (Eds.), Neoproterozoic-Cambrian Tectonics, Global Change and Evolution. Elsevier, Amsterdam, pp. 319-326.

Gorceix, H., 1884. Bacias terciárias d'agua doce nos arredores de Ouro Preto (Gandarela e Fonseca), Minas Gerais, Brasil. Annaes da Escola de Minas 3, 95-114.

Grant, S.W.F., 1990. Shell structure and idstribution of Cloudina, a potential fossil index for the terminal Proterozoic. American Journal of Science 290-A, 261-294.

Grossi Sad, J.H., Cardoso, R.N., da Costa, M.T., 1971. Formações cretácicas em Minas Gerais: uma revisão. Revista Brasileira de Geociências 1, 2-13.

Grotzinger, J.P., Knoll, A.H., 1999. Stromatolites in Precambrian carbonates: evolutionary mileposts or environmental dipsticks. Annual Review of Earth and Planetary Sciences 27, 313-358.

IGA, 1982. Folha Esmeraldas (SE-23-Z-C-V-3). IGA - Instituto de Geociências Aplicadas, Belo Horizonte.

Iglesias, M., Uhlein, A., 2009. Estratigrafia do Grupo Bambuí e coberturas fanerozóicas no vale do rio São Francisco, norte de Minas Gerais. Revista Brasileira de Geociências 39, 256266

Johnson, E.W., Briggs, D.E.G., Suthren, R.J., Wright, J.L., Tunnicliff, S.P., 1994. Non-marine arthropod traces from the subaerial Ordovician Borrowdale Volcanic Group, English Lake District. Geological Magazine 131, 395-406.

Kattah, S.S., 1991. Analise Faciológica e Estratigráfica do Jurássico Superior/Cretácio Inferior na Porção Meridional da Bacia Sanfranciscana, Oeste do Estado de Minas Gerais. Tese de Mestrado, Universidade Federal de Ouro Preto. 227 pp.

Kattah, S.S., 1992. Novas considerações sobre o Aptiano-Albiano da Bacia Sanfranciscana. In: $2^{\circ}$ Simpósio sobre as Bacias Cretácicas Brasileiras, Rio Claro, p. 118-119.

Kattah, S.S., Koutsoukos, E.A.M., 1992. Ocorrencias de radiolários em fácies de origem marinha no Mesozóico da Bacia Sanfranciscana. Revista da Escola de Minas 45, 214.

Keighley, D.G., Pickerill, R.K., 1996. Small Cruziana, rusophycus, and related ichnotaxa from eastern Canada: the nomenclatural debate and systematic ichnology. Ichnos 4, 261-285.

Kennard, J.M., James, N.P., 1986. Thrombolites and stromatolites: two disctinct types of microbial structures. Palaios 1, 492503.

Knauer, L.G., Fantinel, L.M., Costa, R.D., Romano, A.W., Santos Júnior, A.G., Horta, R.M., 2013. FOLHA IBIAÍ - SE.23-X-A-IV. CODEMIG, Belo Horizonte.

Kuchenbecker, M., 2011. Folha Luz - SE.23-Y-D-V. CODEMIG, p. 1:100.000

Kuchenbecker, M., 2014. Relações entre coberturas do Cráton do São Francisco e bacias situadas em orógenos marginais: o registro de datações $\mathrm{U}-\mathrm{Pb}$ de grãos detríticos de zircão e suas implicações geotectônicas. Tese de Doutorado, Universidade Federal de Minas Gerais. 175 pp.

Kuchenbecker, M., Atman, D., Costa, R.D., 2013. Folha Barreiro da Jaíba - SD.23-Z-C-VI. CODEMIG.

Kuchenbecker, M., Costa, R.D., 2013. Folha Capitão Enéas - SE.23X-A-III. CODEMIG.
Kuchenbecker, M., Fantinel, L.M., Fairchild, T.R., Rohn, R., 2015a. Microbialitos da Formação Fecho do Funil (Paleoproterozoico) na Pedreira Cumbi, Quadrilátero Ferrífero (MG), In: Fairchild, T.R., Rohn, R., Dias-Brito, D. (Eds.), Microbialitos do Brasil do Pré-Cambriano ao Recente: Um Atlas. UNESP, IGCE, UNESPetro, Rio Claro, pp. 76-89.

Kuchenbecker, M., Lopes-Silva, L., Pedrosa-Soares, A.C., Babinski, M., 2011. Estratigrafia da porção basal do Grupo Bambuí na região de $\operatorname{Arcos}(M G)$ : uma contribuição a partir de testemunhos de sondagem. Geologia USP Série Científica 11, 45-54.

Kuchenbecker, M., Pedrosa-Soares, A.C., Babinski, M., Fanning, M., 2015b. Detrital zircon age patterns and provenance assessment for pre-glacial to post-glacial successions of the Neoproterozoic Macaúbas Group, Araçuaí orogen, Brazil. Precambrian Research 266, 12-26.

Lacovara, K.J., Lamanna, M.C., Ibiricu, L.M., Poole, J.C., Schroeter E.R., Ullmann, P.V., Voegele, K.K., Boles, Z.M., Carter, A.M., Fowler, E.K., Egerton, V.M., Moyer, A.E., Coughenour, C.L., Schein, J.P., Harris, J.D., Martínez, R.D., Novas, F.E., 2014. A Gigantic, Exceptionally Complete Titanosaurian Sauropod Dinosaur from Southern Patagonia, Argentina. Scientific Reports 4, 1-9.

Liais, E., 1872. Climats Géologie, Faune et Géographie Botanique du Brésil. Garnier Frères, Paris. 640 pp.

Lima, M.R., 1979. Palinologia dos calcários laminados da Formação Areado, Cretáceo de Minas Gerais. In: 2o Simpósio Regional de Geologia, Atas, Rio Claro, p. 203-216.

Lima, M.R., Salard-Cheboldaeff, M., 1981. Palynologie des bassins de Gandarela et Fonseca (Eocene de l'Etat de Minas Gerais, Bresil). Boletim do Insituto Geológico 12, 33-53.

Lima, O.N.B., Uhlein, A., de Britto, W., 2007. Estratigrafia do Grupo Bambuí na Serra da Saudade e geologia do depósito fosfático de Cedro do Abaeté, Minas Gerais. Revista Brasileira de Geociências 37, 204-215.

Lindoso, R.M., Medeiros, M.A., Carvalho, I.S., Marinho, T.S., 2012. Masiakasaurus-like theropod teeth from the Alcântara Formation, São Luís Basin (Cenomanian), northeastern Brazil. Cretaceous Research 36, 119-124.

Logan, B.W., Rezak, R., Ginsburg, R.N., 1964. Classification and environmental significance of algal stromatolites. The Journal of Geology 72, 68-83.

Lopes, J.N., 1995. Faciologia e gênese dos carbonatos do Grupo Bambuí na região de Arcos, estado de Minas Gerais. Tese de Mestrado, Universidade de São Paulo. 166 pp.

Lund, P.W., 1950. Memórias sobre a Paleontologia Brasileira. Instituto Nacional do Livro, Rio de Janeiro. 552 pp.

Machado, M.S., 2004. Análise da Paleobiota do Grupo Areado, Cretáceo da Bacia Sanfranciscana e sua correlação com outras bacias sedimentares Tese de Mestrado, Universidade Estadual do Rio de Janeiro. XXX pp.

Maizatto, J.R., 2001. Análise bioestratigráfica, paleoecológica e sedimentológica das bacias terciárias do Gandarela e Fonseca - Quadrilátero Ferrífero - Minas Gerais, com base nos aspectos palinológicos e sedimentares. Tese de Doutorado, Universidade Federal de Ouro Preto. 249 pp.

Marchese, H.G., 1974. Estromatolitos "gymnosolenidos" en el lado oriental de Minas Gerais, Brasil. Revista Brasileira de Geociências 4, 257-271.

Martins-Neto, M.A., Pedrosa-Soares, A.C., Lima, S.A.A., 2001 Tectono-sedimentary evolution of sedimentary basins from Late Paleoproterozoic to Late Neoproterozoic in the São Francisco craton and Araçuaí fold belt, eastern Brazil. Sedimentary Geology 141-142, 343-370. 
Martins-Neto, R.G., 1996. Reinterpretação da venação e revisão das categorias taxonômicas superiores de Gondvanoptilon brasiliensis ( $=G$. brasiliense nom. transl.) Rösler, Rohn \& Albamonte, inseto do Paleozóico da Bacia do Paraná e Saucrolus silvai Santos, artrópode do Cretáceo da Bacia Sanfranciscana. Revista Universidade de Guarulhos, Série Geociências 1, 42-45.

Martins-Neto, R.G., 2001. Review of some Insecta from Mesozoic and Cenozoic Brazilian deposits with descriptions of new taxa. Acta Geologia Leopoldensia 24, 115-124.

Martins Neto, R.G., 2005. Estágio atual da paleoartropodologia brasileira: hexápodes, miriápodes, crustáceos (Isopoda Decapoda, Eucrustácea e Copepoda) e quelicerados. Arquivos do Museu Nacional 63, 471-494.

Medeiros, M.A., Schultz, C.L., 2002. The dinosaurian fauna of "Laje do Coringa", Middle Cretaceous of Northeastern Brazil. Arquivos do Museu Nacional Rio de Janeiro 60, 155-162.

Mello, C.L., Bergqvist, L.P., Sant'Anna, L.G., 2002. Fonseca, MG Vegetais fósseis do Terciário brasileiro, In: Schobbenhaus, $C$. Campos, D.A., Queiroz, E.T., Winge, M., Berbert-Born, M. (Eds.), Sítios Geológicos e Paleontológicos do Brasil. DNPM CPRM SIGEP, Brasília, pp. 73-79.

Mendonça, K.R.N., 1999. Análise paleogeográfica dos sedimentos do Grupo Areado da Bacia Sanfranciscana na carta topografica de Presidente Olegário, Minas Gerais. Tese de Mestrado, Universidade Federal de Minas Gerais. 73 pp.

Mendonça, K.R.N., 2003. Estratigrafia de Seqüências da Formação Areado na porção sul da Bacia Sanfranciscana, sul de Minas Gerais. Tese de Doutorado, Universidade Federal de Minas Gerais. $124 \mathrm{pp}$.

Meyer, K.E.B., Cassino, R.F., Lorente, F.L., Raczka, M., Parizzi, M.G., 2014. Paleoclima e paleoambiente do cerrado durante - Quaternário com base em análises palinológicas, In: Carvalho, I.S., Garcia, M.J., Lana, C.C., Strochschoen Jr, O. (Eds.), Paleontologia: Cenários de Vida. Interciência, Rio de Janeiro, pp. 403-420.

Moeri, E., 1972. On a columnar stromatolite in the Precambrian Bambui Group of Central Brazil. Eclogae Geologicae Helvetiae 65, 185-195.

Moraes, L.C., Seer, H.I., Fogaca, A.C.C., Sgarbi, P.B.A., Sgarbi, G.N.C., 1986. Geologia das unidades cretáceas da area compreendida entre Lagoa Formosa e Carmo do Paranaíba. In: XXXIV Congresso Brasileiro de Geologia, Anais, p. 337-345.

Nobre, J., Coimbra, A.M., 2000. Microfitólitos associados a construções estromatolíticas do Grupo Bambuí, Proterozóico Superior, na região de Arcos - MG. Revista Brasileira de Geociências 30, 589-592.

Noce, C.M., Pedrosa-Soares, A.C., Grossi Sad, J.H., Baars, F.J., Guimarães, M.L.V., Mourão, M.A.A., Oliveira, M.J.R., Roque, N.C., 1993. Nova divisão estratigráfica regional do Grupo Macaúbas na Faixa Araçuaí: o registro de uma bacia neoproterozóica. Boletim do Núcleo Minas Gerais da Sociedade Brasileira de Geologia 14, 29-31.

Nogueira, G.M.S., Dardenne, M.A., 1992. Caracterização dos dolomitos biohermais estromatolíticos da Região de Lagamar. In: 370 Congresso Brasileiro de Geologia, Boletim dos Resumos Expandidos 1, São Paulo, p. 70-71.

Oliveira, A.A.K., Valle, C.R.O., Féboli, W.L., 2003. Folha SE.23-V-DIV - João Pinheiro. CPRM, p. 1:100.000.

Paula-Santos, G.M., Babinski, M., Kuchenbecker, M., CaetanoFilho, S., Trindade, R.I., Pedrosa-Soares, A.C., in press. New evidence of an Ediacaran age for the Bambuí Group in southern São Francisco craton (eastern Brazil) from zircon U$\mathrm{Pb}$ data and isotope chemostratigraphy. Gondwana Research.
Pedrosa-Soares, A.C., Babinski, M., Noce, C., Martins, M., Queiroga, G., Vilela, F., 2011. The Neoproterozoic Macaúbas Group (Araçuaí orogen, SE Brazil) with emphasis on the diamictite formations, In: Arnaud, E., Halverson, G., Shields, G. (Eds.), The Geological Record of Neoproterozoic Glaciations. Geological Society of London, London, pp. 523534.

Pessagno Jr., E.A., Dias-Brito, D., 1996. O silexito a radiolários do sul da Bacia Sanfranciscana, Brasil: idade, origem e significado. In: 40 Simpósio sobre o Cretáceo do Brasil, Boletim, Águas de São Pedro, p. 213-221.

Pessagno Jr., E.A., Dias-Brito, D., Castro, J.C., 1997. Tectonostratigraphic significance of radiolarian chert in Lower Cretaceous continental sequence, Minas Gerais, Brazil. In: GSA Annual Meeting, 29, Utah, p. 374

Pimentel, M.M., Giustina, M.E.S.D., Rodrigues, J.B., Junges, S.L., 2012. Idade dos grupos Araxá e Bambuí: implicações para a evolução da Faixa Brasília. In: 46 Congresso Brasileiro de Geologia Santos, p. CD-Rom.

Pinto, A.D.P., 1984. Estudo e reclassificação dos estromatólitos colunares da Série Minas. Revista da Escola de Minas 37, 4243.

Pires-Domingues, R.A., 2009. Paleogeografia do Alto de Paracatu: o registro geológico dos bone-beds de dinossauros da Bacia Sanfranciscana. Tese de Mestrado, Universidade de São Paulo. 110 pp.

Popov, Y.A., Bechley, G., 2007. 11.15 Heteroptera: bugs, In: Martill, D.M., Bechley, G., Loveridge, R.F. (Eds.), The Crato Fossil Beds of Brazil: Window to an Ancient World. Cambridge Uniuversity Press, Cambridge, pp. 317-328.

Poropat, S.F., Upchurch, P., Mannion, P.D., Hocknull, S.A., Kear, B.P., Sloan, T., Sinapius, G.H.K., Elliott, D.A., 2015. Revision of the sauropod dinosaur Diamantinasaurus matildae Hocknull et al. 2009 from the mid-Cretaceous of Australia: Implications for Gondwanan titanosauriform dispersal. Gondwana Research 27, 995-1033.

Poyato-Ariza, F.J., Grande, T., Diogo, R., 2010. Gonorynchiform interrelationships: historic overview, analysis, and revised systematics of the group, In: Grande, T., Poyato-Ariza, F.J., Diogo, R. (Eds.), Gonorynchiforms and Ostariophysian Relationships, A Comprehensive Review. Science Publishers, Enfield, pp. 227-337.

Quadros, L.P., 1987. Ocorrência de Acritarchae (microfósseis marinhos) em sedimentos do pré-cambriano na área de Januária, MG, Brasil. Boletim de Geociências da Petrobrás 1, 239.

Reis, H.L.S., 2011. Estratigrafia e tectônica da Bacia do São Francisco na zona de emanações de gás natural do baixo Rio Indaiá (MG). Tese de Mestrado, Universidade Federal de Ouro Preto. 156 pp.

Renger, F.E., Noce, C.M., Romano, A.W., Machado, N., 1994. Evolução sedimentar do Supergrupo Minas: $500 \mathrm{Ma}$ de registro geológico no Quadrilátero Ferrífero, Minas Gerais, Brasil. Geonomos 2, 1-11.

Ribeiro, A.C., Bockmann, F.A., Carvalho, M.R., 2005. Revision of Dastilbe moraesi Silva Santos, 1955 (Ostariophysi: Chanidae), a valid species from the Areado Formation, Early Cretaceous of Brazil. In: Fourth International Meeting on Mesozoic Fishes - Systematic, Homology, and Nomenclature, Miraflores de la Sierra, p. 221-226.

Riding, R., 2007. The term stromatolite: towards an essential definition. Lethaia 32, 321-330. 
Riding, R., 2011. Microbialites, Stromatolites, and Thrombolites, In: Reitner, J., Thiel, V. (Eds.), Encyclopedia of Geobiology. Springer Netherlands, pp. 635-654.

Riding, R.E., 1999. The term stromatolite: towards an essential definition. Lethaia 32, 321-330.

Rodrigues, J.B., Pimentel, M.M., Buhn, B., Matteini, M., Dardenne, M.A., Alvarenga, C.J.S., Armstrong, R.A., 2012. Provenance of the Vazante Group: New U-Pb, Sm-Nd, Lu-Hf isotopic data and implications for the tectonic evolution of the Neoproterozoic Brasília Belt. Gondwana Research 21, 439450.

Rohn, R., Cavalheiro, M.C.T., 1996. Conchostráceos cretácicos da Bacia de Tucano (Bahia) e avaliações do potencial cronoestratigráfico destes crustáceos no Mesozóico do Brasil. In: 40 Simpósio sobre o Cretáceo do Brasil, Boletim, Águas de São Pedro, p. 157-167.

Sallun Filho, W., Fairchild, T.R., 2005. Estudo comparativo entre estromatólitos do tipo Conophyton das faixas Ribeira e Brasília. Revista do Instituto Geológico 26, 1-18.

Sanchez, E.A.M., 2014. Microbialitos e microfósseis da Formação Sete Lagoas, Neoproterozoico, Brasil: implicações geomicrobiológicas em um contexto de mudanças climáticas e evolutivas. Tese de Tese de Doutorado, Universidade de São Paulo. pp.

Sant'Anna, L.G., Schorscher, H.D., 1997. Estratigrafia e mineralogia dos depósitos cenozóicos da região da Bacia de Fonseca, Estado de Minas Gerais, Brasil. Anais da Academia Brasileira de Ciências 69, 211-226.

Santos, M.E.C.M., 1971. Um nôvo artrópodo da Formação Areado, Estado de Minas Gerais. Anais da Academia Brasileira de Ciências 43, 415-420.

Santos, R.S., 1985. Laeliichthys ancestralis, novo gênero e espécies de Osteoglossiformes do Aptiano da Formação Areado, estado de Minas Gerais, Brasil, In: Campos, D.A., Ferreira, C.S., Brito, I.M., Viana, C.F. (Eds.), Paleontologia e Estratigrafia, Coletânea de Trabalhos Paleontológicos. DNPM, Brasília, pp. 161-167.

Santucci, R.M., Pinto, R.L., Almeida, M.F., Souza, L.M., Mineiro, A.S., Santos, D.M., 2014. Um dente de terópode da Formação Quiricó, Bacia Sanfranciscana (Aptiano) do norte de Minas Gerais. In: IX Simpósio Brasileiro de Paleontologia de Vertebrados, Vitória, p. 124

Schöll, W.R., 1976. Estromatólitos (Conophyton) em dolomitos do Grupo Macaúbas. In: 29 Congresso Brasileiro de Geologia, Resumos, Ouro Preto, p. 363.

Schöll, W.U., Fogaça, C.A.C., 1980. Estromatólitos em dolomitos do Grupo Macaúbas (Supergrupo São Francisco) na região de Conselheiro Mata, M.G. . Boletim IG 11, 40-42.

Scorza, F.P., Santos, R.S., 1955. Ocorrência de folhelho fossilifero no município de Presidente Olegário, Minas Gerais. Boletim do Departamento Nacional de Produção Mineral - Divisão de Geologia e Mineralogia 155, 1-27.

Seer, H.I., Moraes, L.C., 2011. Folha Campos Altos - SE.23-Y-D-IV. CODEMIG, p. 1:100.000

Sgarbi, G.N.C., 1989. Geologia da Formação Areado, Cretáceo Médio a Inferior da Bacia do São Francisco, oeste do Estado de Minas Gerais. Tese de Mestrado, Universidade Federal do Rio de Janeiro. 324 pp.

Sgarbi, G.N.C., 1991. Arenitos eólicos da Formação Areado (Bacia cretácea do São Francisco): caracterização, diagênese e aspectos químicos. Revista Brasileira de Geociências 21, 342354.
Sgarbi, G.N.C., 1997. Aspectos paleogeográficos e sedimentológicos do Mesozóico no oeste do estado de Minas Gerais Tese de Doutorado, Universidade de Brasília. 224 pp.

Sgarbi, G.N.C., Fantinel, L.M., Masotti, F.S., 1992. Geologia dos sedimentos lacustres da Bacia terciária do Gandarela. Revista da Escola de Minas 45, 118-122.

Sgarbi, G.N.C., Sgarbi, P.B.A., Campos, J.E.G., Dardenne, M.A., Penha, U.C., 2001. Bacia Sanfranciscana: o registro Fanerozóico da Bacia do São Francisco In: Pinto, C.P., Martins-Neto, M.A. (Eds.), Bacia do São Francisco: Geologia e Recursos Naturais. SBG, Belo Horizonte, pp. 93-138.

Shear, W.A., Edgecombe, G.D., 2010. The geological record and phylogeny of the Myriapoda. Arthropod Structure \& Development 39, 174-190.

Silva, H.M.A., Gallo, V., 2012. Teleósteos fósseis do Brasil, In: Carneiro, C.D.R., Almeida, F.F.M., Bartorelli, A. (Eds.), Geologia do Brasil. Beca, São Paulo, pp. 722-730.

Silva, R.R., 2013. Descrição osteológica e posicionamento filogenético de um terópode (Dinosauria, Saurischia) do Cretáceo Inferior da Bacia Sanfranciscana, município de Coração de Jesus, Minas Gerais, Brasil. Tese de Mestrado, Universidade de São Paulo. 121 pp.

Simonetti, C., Fairchild, T.R., 1989. Paleobiologia de uma nova microflórula silicificada do Grupo Bambuí (Proterozóico Superior) da região de Unaí, MG. Boletim IG-USP, Publicação Especial 7, 1-26.

Simonetti, C., Fairchild, T.R., 2000. Proterozoic microfossils from subsurface siliciclastic rocks of the São Francisco Craton, south-central Brazil. Precambrian Research 103, 1-29.

Sommer, F.W., 1971. Microfósseis do Calcário Bambuí, de Pedro Leopoldo, estado de Minas Gerais. Anais da Academia Brasileira de Ciências 43, 135-139.

Souza, P.C., Müller, G., 1984. Primeiras estruturas algais comprovadas na Formação Gandarela, Quadrilátero Ferrífero. Revista da Escola de Minas 37, 13-21.

Suguio, K., Barcelos, J.H., 1983. Paleoclimatic evidence from the Areado Formation, Cretaceous of the Sanfranciscana Basin state of Minas Gerais, Brazil. Revista Brasileira de Geociências $13,229-231$.

Tassi, L.V., 2010. Estudo tafonômico de icnofósseis atribuíveis à diplóplodos (Myriapoda) no Parque Municipal do Varvito, município de Itu (São Paulo, Brasil) Tese de Mestrado, Universidade Federal de Juiz de Fora. 75 pp.

Tucker, M.E., Wright, V.P., 1990. Carbonate Sedimentology. Blackwell Science, Oxford. 482 pp.

Uhlein, A., Baptista, M.C., Seer, H.I., Caxito, F.A., Uhlein, G.J., Dardenne, M.A., 2011. A Formação Lagoa Formosa, Grupo Bambuí (MG): sistema deposicional de leque submarino em bacia de ante-país. Geonomos 19, 163-172.

Uhlein, A., Reis Jr, W., Freitas, A.R., Uhlein, G.J., Ávilla, M.A.B., 2013. Folha Ubaí - SE.23-X-A-I. CODEMIG.

Uhlein, G.J., Moreira, G.C., Uhlein, A., Meyer, K.E.B., Trompette, R.R., 2010. Ocorrência de icnofósseis Ediacranos (Skolithos?) na Formação Salinas, Grupo Macaúbas, Minas Gerais. In: 45o Congresso Brasileiro de Geologia, Belém, p. 1004.

Valeriano, C.M., Dardenne, M.A., Fonseca, M.A., Simões, L.S.A., Seer, H.J., 2004. A evolução tectônica da Faixa Brasília, In: Mantesso-Neto, V., Bartorelli, A., Carneiro, C.D.R., Brito Neves, B.B. (Eds.), Geologia do continente sul-americano: evolução da obra de Fernando Flávio Marques de Almeida. Beca, São Paulo, pp. 575-592. 
Vieira, L.C., Almeida, R.P., Trindade, R.I.F., Nogueira, A.C.R., Janikian, L., 2007. A Formação Sete Lagoas em sua área-tipo: fácies, estratigrafia e sistemas deposicionais. Revista Brasileira de Geociências 37, 1-14.

Vieira, P.L.C.R., Horta, R.M., Bittencourt, J., 2015. Geologia da região de Lagoa dos Patos, norte de Minas Gerais, e seu potencial paleontológico. In: Geosudeste 2015, Anais, Campos do Jordão, p. 142.
Warren, L.V., Quaglio, F., Riccomini, C., Simões, M.G., Poiré, D.G., Strikis, N.M., Anelli, L.E., Strikis, P.C., 2014. The puzzle assembled: Ediacaran guide fossil Cloudina reveals an old proto-Gondwana seaway. Geology 42, 391-394.

Zaher, H., Pol, D., Carvalho, A.B., Nascimento, P.M., Riccomini, C., Larson, P., Juarez-Valieri, R., Pires-Domingues, R., Silva Jr., N.J.d., Campos, D.A., 2011. A complete skull of an Early Cretaceous sauropod and the evolution of advanced titanosaurians. PlosOne 6, 1-10. 